Federal Reserve Bank of Minneapolis

Research Department

\title{
Taxation, Aggregates and the Household
}

\author{
Nezih Guner, Remzi Kaygusuz, \\ and Gustavo Ventura ${ }^{1}$
}

Working Paper 660

April 2008

\begin{abstract}
We evaluate reforms to the U.S. tax system in a dynamic setup with heterogeneous married and single households, and with an operative extensive margin in labor supply. We restrict our model with observations on gender and skill premia, labor force participation of married females across skill groups, and the structure of marital sorting. We study four revenue-neutral tax reforms: a proportional consumption tax, a proportional income tax, a progressive consumption tax, and a reform in which married individuals file taxes separately. Our findings indicate that tax reforms are accompanied by large and differential effects on labor supply: while hours per-worker display small increases, total hours and female labor force participation increase substantially. Married females account for more than $50 \%$ of the changes in hours associated to reforms, and their importance increases sharply for values of the intertemporal labor supply elasticity on the low side of empirical estimates. Tax reforms in a standard version of the model result in output gains that are up to $15 \%$ lower than in our benchmark economy
\end{abstract}

JEL classification numbers: E62, H31, J12, J22

Key words: Taxation, Two-earner Households, Labor Force Participation.

${ }^{1}$ Guner, Department of Economics, Universidad Carlos III de Madrid, Calle Madrid 126, Getafe (Madrid), 28903, Spain, CEPR and IZA; Kaygusuz, Faculty of Arts and Social Sciences, Sabanci University, 34956, Istanbul, Turkey; Ventura, Department of Economics, University of Iowa, 358 PBB, Iowa City, IA 52242-1994, USA. We thank participants at the Dynamic General Equilibrium Macroeconomics Workshop in Santiago de Compostela, NBER Summer Institute (Aggregate Implications of Microeconomic Consumption Behavior, Macro Perspectives), SED, Midwest Macro Conference, LACEA Meetings, "Households, Gender and Fertility: Macroeconomic Perspectives" Conference in UC-Santa Barbara, "Research on Money and Markets" Conference at Toronto, Federal Reserve Banks of Richmond and Minneapolis, IIES (Stockholm), IZA (Bonn), Bilkent (Ankara), Concordia, Illinois, Indiana, Purdue, Sabanci and Wisconsin for helpful comments. We thank the Population Research Institute at Pennsylvania State for support. Guner thanks Instituto de Estudios Fiscales (Ministerio de Economia y Hacienda), Spain, and Ministerio de Educacion y Ciencia, Spain, Grant SEJ2007-65169 for support. The views expressed herein are those of the authors and not necessarily those of the Federal Reserve Bank of Minneapolis or the Federal Reserve System. 


\section{Introduction}

Tax reforms have been at the center of numerous debates among academic economists and policy makers. These debates have been fueled by theoretical results establishing that taxing capital income might not be efficient, by equity and economic efficiency trade-offs, and by the fact that the current U.S. tax structure is complicated and distortionary. As a part of this debate, there have been calls for tax reforms that would simplify the tax code, change the tax base from income to consumption, and adopt a more uniform marginal tax rate structure. $^{2}$

In the existing literature, the decision maker is typically an individual who decides how much to work, how much to save, and in some cases how much human capital investments to make. Yet, current households are neither a collection of breadwinner husbands and homemaker wives, nor a collection of single people. In 2000, the labor force participation of married women between ages 25 and 54 was about $69 \%$. Furthermore, their participation rate increases markedly by educational attainment, and is known to respond strongly to hourly wages. Moreover, the economic environment that these households face does not feature wages that are gender-neutral. Hourly earnings of females relative to males, the gender gap, is about $72 \%$ nowadays and has been around this value for some time. ${ }^{3}$

These observations have long been deemed important in discussions of tax reforms, but are largely unexplored in dynamic equilibrium analyses in the macroeconomic and publicfinance literatures. We fill this void in this paper. We quantify the effects of tax reforms taking into account the labor supply of married females as well as the current demographic (household) structure. For these purposes, we develop a dynamic equilibrium model with an operative extensive margin in labor supply, and a structure of individual and household heterogeneity that is consistent with the current U.S. demographics. We use this framework to conduct a set of hypothetical tax reform experiments, and ask: What is the importance of the labor supply responses of married females in these experiments? What is the importance of micro labor supply elasticities for the long-run effects on output and the labor input? How do our results compare to those emerging from a standard (single-earner) macroeconomic model?

\footnotetext{
${ }^{2}$ Among such reform proposals, one can list Hall and Rabushka's (1995) flat tax, a proportional income tax or a proportional consumption tax - see Auerbach and Hassett (2005) for a review.

${ }^{3}$ Our calculations. See Section 4 for details.
} 
The model economy we consider is populated with males and females who differ in their labor market productivities, and who exhibit life-cycle behavior. Individuals start economic life as either married or single and do not change their marital status as they age. They are born as workers with given, immutable labor market efficiencies, and stochastically transit into retirement and subsequently to death. Hence, in the model agents differ along their gender, labor productivity, and marital status. Singles decide how much to work and how much to save out of their total after-tax income. Married households decide on the labor hours of each household member, and like singles, how much to save.

A novel feature in our analysis is the explicit modeling of the participation decision of married females in two-person households, and its interplay with the structure of heterogeneity and taxation. We assume that if a married female enters the labor force, the household faces a utility cost. This cost represents the additional difficulty originating from the need to better coordinate multiple household activities, potential child-care costs, etc. As a result, females in married households may choose not to work at all if this utility cost is sufficiently high, which naturally generates labor supply movements along the extensive margin. This is a key feature of our analysis since the structure of taxation can affect the participation decision of married females, and available evidence suggests that it does so significantly. Our model thus permits us to separate and quantify changes in labor supply that take place at extensive and intensive margins.

We restrict model parameters so that our benchmark economy is consistent with relevant aggregate and cross-sectional U.S. data. Three aspects of our parameterization are critical. First, using data on tax returns we estimate effective tax functions for married and single households. These functions relate taxes paid to reported incomes, and are able to capture the complex relation between household incomes and taxes in a parsimonious way. Second, we calibrate our benchmark economy to be consistent both with available estimates of intertemporal elasticities of labor supply along the intensive margin, and with observations on the labor force participation of married females. In particular, we select parameter values so that the labor force participation of married females reacts to their own wages as it does in the data. This aspect of our parameterization is crucial since it allows us to capture the underlying elasticities of labor force participation of married females. Finally, the demographic structure of the model is tightly mapped to U.S. observations. The marital structure of the benchmark economy (who is single, who is married, and who is married with whom) 
reproduces exactly the structure observed in the U.S. Census. This is of importance for our purposes; different households face different average and marginal tax rates, and reactions of different households to a tax reform are potentially not the same.

We consider four revenue-neutral tax reforms. Three of these reforms are fundamental in nature: a proportional consumption tax, a proportional income tax, and a progressive consumption tax, e.g., Hall and Rabushka (1995), which consists of a single tax rate above an exemption level. In our last reform (separate filing), we keep the progressivity and the tax base of the current system intact, but married individuals file taxes separately. This reform, which arises naturally in our environment, shifts the unit subject to taxation from households to individuals. As a result, it can drastically change marginal tax rates within married households, while effectively eliminating tax penalties (and bonuses) associated to marital status built into the current tax code.

In line with the existing literature, we find that tax reforms can have large effects across steady states on macroeconomic variables, such as output and capital intensity. A central finding of our exercises is that the differential labor supply behavior of different groups is key for an understanding of the aggregate effects of tax reforms. The related finding is that married females account for a disproportionate fraction of the changes in hours and labor supply. Furthermore, this fraction increases sharply for low values of the intertemporal elasticity of labor supply.

Replacing current income taxes by a proportional consumption (income) tax increases the aggregate output by about $11.2 \%$ (5.9\%). This increase is accompanied by differential effects on labor supply: while hours along the intensive margin increase by about $2.7 \%(2.4 \%)$, the labor force participation of married females increases by about $7.3 \%$ (6.2\%) and married females increase their total hours by $10.6 \%$ (9.3\%). Both reforms have similar effects on labor supply, which suggests that the flattening of the tax schedule is what really matters for labor supply behavior. On the other hand, their effects on capital accumulation differ significantly, which is reflected in how much aggregate output rises.

The effects of a progressive consumption tax reform are different. The aggregate effects are more moderate and the positive effects on labor force participation of married females are much less pronounced. If the exemption level associated with the progressive consumption tax reform is relatively high (higher degree of progressivity), aggregate output increases only by about $8.0 \%$ (as opposed to $11.2 \%$ with a proportional consumption tax reform). The rise 
in the labor force participation of married females is also less pronounced than the proportional consumption tax reform and is only $3.2 \%$ (instead of $7.3 \%$ ). With proportional taxes, the rise in labor force participation monotonically declines as the productivity of married females increases. This is not the case for a progressive consumption tax. Females with low productivity levels change their labor supply very little after a progressive consumption tax reform. Hence, the way tax reforms affect labor supply of married females depends crucially of the structure on the particular reform under consideration.

Finally, separate filing goes a long way in generating significant aggregate output effects. With separate filing, aggregate output goes up by about $2.6 \%$, which is almost half of the increase from a proportional income tax reform. The increase in aggregate output mainly comes from the rise in aggregate hours by married females. The labor force participation of married females rises close to what it does under a proportional income (consumption) tax reform: an increase of $5.9 \%$ versus $6.2 \%$ (7.3\%). In contrast to other reforms, hours per male workers are nearly constant, and the increase capital to output ratio is much more moderate.

In answering the first question posed above, "What is the importance of the labor supply responses of married females in these experiments?,"we find that married females account for a disproportionate fraction of the changes in hours and labor supply. Under proportional taxes, married females account for about 58-59\% of the total increase in labor hours, and about $49-50 \%$ of the aggregate increase in labor supply (efficiency units). Under progressive consumption taxes, married females contribute even more significantly to changes in labor hours and labor supply; in our exercises married females can account for up to $80 \%$ and $65 \%$ of the total changes in total working hours and labor supply, respectively. Finally, with separate filing almost all of the rise in hours and labor supply comes from married females, as their contribution is about $92 \%$ of total change in hours and $89 \%$ of the total change in labor supply.

In answering the second question, "What is the importance of micro labor supply elasticities for the long-run effects on output and the labor input,?"we find that the importance of married females rises sharply when the parameter governing the intertemporal labor supply elasticity is lowered from our benchmark value of 0.4 to 0.2 . In this case, the contribution of married females to changes in labor hours is quite higher, ranging from $76 \%$ to $98 \%$ across different reforms, and is driven mostly by changes in participation. While the relative importance of female labor supply becomes much more important, the rise in the total labor input 
remains relatively constant as we alter the value of the intertemporal labor supply elasticity. Then, a central finding is that the value of this preference parameter is of second-order importance in understanding the effects on labor supply associated to tax reforms.

Finally, in terms of the third question, "How do our results compare to those emerging from a standard (single-earner) macroeconomic model,?"we find that reforms introduced to a version of our economy that mimics a standard macroeconomic model generates only a fraction of the long-run output gains. For a proportional consumption tax, the standard model generates only $85 \%-89 \%$ of the changes in output implied by our framework. Thus, tax reform exercises in the context of macroeconomic models with single earners can be misleading if low labor supply elasticities are used.

Background There are several reasons that point to the relevance of our analysis. First, in the current U.S. tax system the household (not the individual) constitutes the basic unit of taxation, which may result in high tax rates on secondary earners. A single woman's taxes depend only on her own income. Yet, when a married female considers entering the labor market, the first dollar of her earned income is taxed at her husband's current marginal rate. Second, from a conceptual standpoint, wages of each member in a two-person household affect joint labor supply decisions as well as the reactions to changes in the tax structure. Thus, the degree of marital sorting (who is married to whom) could affect the aggregate responses to alternative tax rules. Finally, a common view among many economists has been that tax changes may have moderate impacts on labor supply. This view is supported by empirical findings on the low or near zero labor supply elasticities of prime-age males. Recent developments, however, started to challenge this wisdom. Tax reforms in the 1980's have been shown to affect female labor supply behavior significantly, but have relatively small effects on males (Bosworth and Burtless (1992), Triest (1990), and Eissa (1995)). More recently, Eissa and Hoynes (2006) show that the disincentives to work embedded in the Earned Income Tax Credit (EITC) for married women are quite significant (effectively subsidizing some married women to stay at home). These findings are consistent with ample empirical evidence that female labor supply in general, and female labor force participation in particular are quite elastic (Blundell and MaCurdy (1999)); they point in the direction of modeling explicitly household labor choices. If households, not individuals, react to taxes much more than previously thought, the potential effects of tax reforms can 
be more significant.

Our work largely builds on two main strands of literature. First, our evaluation of tax reforms using a dynamic model with heterogeneity follows the work by Ventura (1999), Altig, Auerbach, Kotlikoff, Smetters and Walliser (2001), Castañeda, Díaz-Jiménez and RíosRull (2003), Díaz-Jiménez and Pijoan-Mas (2005), Nishiyama and Smetters (2005), Conesa and Krueger (2006), and Erosa and Koreshkova (2007) among others. In contrast to these papers, we study economies populated with married and single households, where married households can have one or two earners. Chade and Ventura (2002) study the effects of tax reforms on labor supply and assortative matching in a model with heterogeneous individuals and endogenous marriage decisions. These authors, however, abstract from labor supply decisions along the extensive margin and capital accumulation. ${ }^{4}$ Second, as in Cho and Rogerson (1988), Mulligan (2001), and Chang and Kim (2006), we study the aggregate effects of changes in labor supply along the extensive margin. We differ from these papers by explicitly analyzing the role of the extensive margin for public policy. ${ }^{5}$

Our paper is also related to two recent literatures. First, it is related to recent work that argues that the structure of taxation can significantly affect labor choices, and play a significant role in accounting for cross-country differences in labor supply behavior. Davis and Henrekson (2003), Olovsson (2003), Prescott (2004), and Rogerson (2006) are examples of papers in this group. Our paper is also related to recent work that studies female labor supply in macroeconomic setups. Jones, Manuelli and McGrattan (2003), Greenwood and Guner (2004), Greenwood, Seshadri and Yorukoglu (2005), Albanesi and Olivetti (2007), Attanasio, Low and Sánchez Marcos (forthcoming) and Knowles (2007) are representative papers in this group.

The paper is organized as follows. Section 2 presents an example that highlights the role of taxation with two-person households, and motivates the parameterization of the model economy. Section 3 presents the model economy. Section 4 discusses the parameterization of the model and the mapping to data. Results from tax reforms are presented in section 5. Section 6 quantifies the role of married females and the extensive margin in labor supply.

\footnotetext{
${ }^{4}$ Kleven and Kreiner (2006) study optimal taxation of two-person households when households face an explicit labor force participation decision.

${ }^{5}$ See Kaygusuz $(2006 \mathrm{a}, 2006 \mathrm{~b})$ for recent analysis of tax and social security policies with an extensive margin in labor supply. See also Hong and Ríos-Rull (2007) for a recent analysis of the role of social security in a framework with married and single households.
} 
Section 7 discusses the implications of a lower labor supply elasticity. Section 8 compares the results of our framework with those in a standard macroeconomic model. Section 9 concludes.

\section{Taxation, Two-Person Households and the Extensive Margin}

In this section, we present a simple two-period example that illustrates how taxes affect labor supply decisions with two-earner households, with an emphasis on the effects on the potential changes in labor force participation. The example serves to highlight key features of our general environment. It also helps in understanding some of the calibration choices we make later.

A one-earner household Consider a married household that lives for two periods (young $(y)$ and old $(o)$ ). Suppose household members work only in the first period and retire in the second one. The household decides whether only one or both members should work in the first period, and how much to save for the retirement. Let $R$ be the gross interest rate on savings, and let $x$ and $z$ denote the labor market productivities (wage rates) of males and females, respectively. Let $\tau$ be a proportional labor tax on first period's labor income.

Consider first the problem if only one member (husband) works. The household problem is given by

$$
\max _{l_{m, 1}, s_{1}}\left\{2[\underbrace{U\left((1-\tau) z l_{m, 1}-s_{1}+T\right)}_{=U\left(c_{y}\right)}+\beta \underbrace{U\left(s_{1} R\right)}_{=U\left(c_{o}\right)}]-W\left(l_{m, 1}\right)\right\},
$$

where $l_{m, 1}$ is the labor choice of the primary earner (husband), $s_{1}$ are assets for next period (savings) and $T$ is a transfer received from the government in the first period. The subscript 1 represents the choices of a one-earner household. The functions $U($.$) and W($.$) stand for$ the instantaneous utility and disutility, associated to household consumption and worktime, respectively. Both functions are differentiable; $U($.$) is strictly concave while W($.$) is strictly$ convex.

We introduce government transfers in order to capture and illustrate in a simple way the role of progressive taxation. This follows as household choices under non-linear, progressive taxes are equivalent to choices under a linear tax system that combines a proportional tax 
rate plus a lump-sum transfer. Under a progressive tax system, changes in marginal tax rates affect labor choices even for preferences for which income and substitution effects cancel out; the same occurs under the linear tax system that we consider.

Household utility when only one member works is given by

$$
V_{1}(\tau)=2\left[U\left((1-\tau) z l_{m, 1}^{*}-s_{1}^{*}+T\right)+\beta U\left(s_{1}^{*} R\right)\right]-W\left(l_{m, 1}^{*}\right)
$$

where $\mathrm{a}^{\prime} *^{\prime}$ denotes an optimal choice.

A two-earner household Now consider the case when both members work. If this occurs, the household incurs a utility cost $q$, drawn from a distribution with c.d.f $\zeta(q)$. Then the problem is given by

$$
\begin{aligned}
\max _{l_{m, 2}, l_{f, 2}, s_{2}} & \left\{2[\underbrace{U\left((1-\tau)\left(z l_{m, 2}+x l_{f, 2}\right)-s_{2}+T\right)}_{=U\left(c_{y}\right)}+\beta \underbrace{U\left(s_{2} R\right)}_{=U\left(c_{o}\right)}]\right. \\
& \left.-W\left(l_{m, 2}\right)-W\left(l_{f, 2}\right)-q\right\},
\end{aligned}
$$

where the subscript 2 represents the choices of a two-earner household. Household utility in this case equals

$$
\begin{aligned}
V_{2}(\tau)-q= & 2\left[U\left((1-\tau)\left(z l_{m, 2}^{*}+x l_{f, 2}^{*}\right)-s_{2}^{*}+T\right)+\beta U\left(s_{2}^{*} R\right)\right] \\
& -W\left(l_{m, 2}^{*}\right)-W\left(l_{f, 2}^{*}\right)-q .
\end{aligned}
$$

Taxes and the extensive margin in labor supply A married household is indifferent between having one and two earners for a sufficiently high value of the utility cost. Hence, there exists a value of $q$, call it $q^{*}$, that obeys $q^{*}=V_{2}(\tau)-V_{1}(\tau)$. For households with a $q$ higher than $q^{*}$ it is optimal to have only one earner, while for those with a $q$ lower than $q^{*}$, it is optimal to be a two-earner household. From this expression, it is clear that $q^{*}$ will change as taxes change. In order to determine how exactly $q^{*}$ changes with taxes, we appeal to the envelope theorem. First note that

$$
\frac{\partial V_{1}(\tau)}{\partial \tau}=-2 U^{\prime}\left((1-\tau) z l_{m, 1}^{*}-s_{1}^{*}+T\right)\left(z l_{m, 1}^{*}\right)<0
$$


Similarly,

$$
\frac{\partial V_{2}(\tau)}{\partial \tau}=-2 U^{\prime}\left((1-\tau)\left(z l_{m, 2}^{*}+x l_{f, 2}^{*}\right)-s_{2}^{*}+T\right)\left(z l_{m, 2}^{*}+x l_{f, 2}^{*}\right)<0 .
$$

Henceforth,

$$
\frac{\partial q^{*}}{\partial \tau}=\frac{\partial V_{2}(\tau)}{\partial \tau}-\frac{\partial V_{1}(\tau)}{\partial \tau}<0,
$$

if and only if

$$
\frac{U^{\prime}\left((1-\tau)\left(z l_{m, 2}^{*}+x l_{f, 2}^{*}\right)-s_{2}^{*}+T\right)}{U^{\prime}\left((1-\tau) z l_{m, 1}^{*}-s_{1}^{*}+T\right)}>\frac{z l_{m, 1}^{*}}{z l_{m, 2}^{*}+x l_{f, 2}^{*}} .
$$

That is, $q^{*}$ and as a result, female labor force participation, will be lower when taxes are high if and only if the above condition holds. Suppose now that $U(c)=\log (c) .{ }^{6}$ In this case, this condition reduces (after some algebra) to

$$
(1-\tau)+\frac{T}{\left(z l_{m, 1}^{*}\right)}>(1-\tau)+\frac{T}{\left(z l_{m, 2}^{*}+x l_{f, 2}^{*}\right)} .
$$

Thus, as long as condition (1) holds, lower (higher) taxes on labor will increase (decrease) the threshold $q^{*}$, and generate a higher (lower) labor force participation of the household's secondary earner. This is illustrated in the top panel of Figure 1. Thus, a change in tax rates affects not only the intensive margin in labor supply but also the extensive margin.

Notice that the above condition necessarily holds in our case. If the transfer and the marginal tax rate are not contingent on the number of earners in the household (as modeled here), then for a given household type, the labor income in the two earner case will be higher than in the first earner case. This follows simply from concavity of the utility function.

We note here three things. First, the fact that the transfer and the marginal tax rate are not contingent on the number of earners in the household captures U.S. tax rules that take the household as the unit of taxation. From this perspective, a reduction in the marginal tax rate on the household is effectively a reduction on the tax rate on secondary earners that may prompt a movement along the extensive margin. Second, the threshold $q^{*}$ changes in response to changes in the tax rate even under log-preferences for consumption, for which income and substitution effects usually cancel out. Here, the presence of the common transfer is essential for the movement in $q^{*}$, as condition (1) shows. When a transfer is present, and

\footnotetext{
${ }^{6}$ This is our case of interest, as we use it in our general environment.
} 
of course more generally under progressive taxation, changes in marginal tax rates affect not only $q^{*}$, but labor supply along the intensive margin. This occurs as income and substitution effects no longer cancel out.

Finally, from this analysis, changes in labor supply (in efficiency units) in response to tax rate changes can be decomposed in two parts: there are changes in labor supply from males and females currently working (intensive margin), and changes due to female labor force participation (extensive margin). Assuming that couples differ only in terms of utility cost they face, aggregate labor supply of married couples $(L)$, can be written as

$$
L=\zeta\left(q^{*}\right)\left[z l_{m, 2}^{*}+x l_{f, 2}^{*}\right]+\left(1-\zeta\left(q^{*}\right)\right) z l_{m, 1}^{*}
$$

Hence, the change in aggregate labor supply from tax rate changes is given by

$$
\frac{\partial L}{\partial \tau}=\underbrace{\zeta\left(q^{*}\right)\left[z \frac{\partial l_{m, 2}^{*}}{\partial \tau}+x \frac{\partial l_{f, 2}^{*}}{\partial \tau}\right]+\left(1-\zeta\left(q^{*}\right)\right) z \frac{\partial l_{m, 1}^{*}}{\partial \tau}}_{\text {intensive margin }}+\underbrace{\zeta^{\prime}\left(q^{*}\right)\left[z l_{m, 2}^{*}+x l_{f, 2}^{*}-z l_{m, 1}^{*}\right] \frac{\partial q^{*}}{\partial \tau}}_{\text {extensive margin }} .
$$

This example has important implications for the mapping of our model economy to the data. As the bottom panel of Figure 1 shows, exactly how much the labor force participation of married females will increase depends on the shape of $\zeta(q)$. Therefore, selecting the functional form for the distribution of utility costs will be a key part of the model parameterization; the magnitude of the response along the extensive margin depends on slope $\zeta^{\prime}(q)$ as equation (2) illustrates. We capture this slope by exploiting the observed changes in female labor force participation in response to changes in the gender gap, $x / z$. The key to this procedure is that an increase in $x$, for a given $z$, implies an increase in labor force participation whose magnitude hinges precisely on the magnitude of $\zeta^{\prime}(q)$.

\section{The Economic Environment}

We study a stationary economy populated by a continuum of males and a continuum of females. The total mass of agents in each gender is normalized to one. As in Gertler (1999), individuals have finite lives that are divided in two stages, work and retirement. In particular, each agent is born as a worker and faces each period a constant probability of retirement $\rho$ 
so that average time spent as a worker is $1 / \rho$. Once an agent retires, he faces a constant risk of death $\delta$ every period so that average time spent in retirement is $1 / \delta$.

Individuals differ in terms of their marital status: they are born either as single or married, and this marital status does not change over time. In addition, members of a married household experience identical life-cycle dynamics, i.e. they retire and die together.

Each period working households (married or single) make joint labor supply, consumption and savings decisions. As in Cho and Rogerson (1988), among other papers, if the female member of a married household supplies positive amounts of market work, then the household incurs a utility cost. This utility cost is drawn once and for all at the start of life and remains constant until the household members retire.

Heterogeneity The labor productivity of a female is denoted by $x \in X$, where $X \subset$ $R_{++}$is a finite set. Similarly, let the labor productivity of a male be denoted by $z \in Z$, where $Z \subset R_{++}$is a finite set. Each agent is born with a particular $z$ or $x$ that remains constant throughout his/her life. Let $\Phi(x)$ and $\Omega(z)$ denote the fractions of type- $x$ females in female population and of type- $z$ males in male population, respectively. Since population of each gender is normalized to one, $\sum_{x \in X} \Phi(x)=1$ and $\sum_{z \in Z} \Omega(z)=1$.

Preferences The momentary utility function for a single person is given by

$$
U^{S}(c, l)=\log (c)-B l^{1+\frac{1}{\gamma}}
$$

where $c$ is consumption and $l$ is time devoted to market work.

Married households maximize the sum of their members' utilities. We assume that when the female member of a married household works, the household incurs a utility cost $q$. Denoting by $\chi\left\{l_{f}\right\}$ the indicator function for joint work, i.e.,

$$
\chi\left\{l_{f}\right\}=\left\{\begin{array}{c}
1, \text { if } l_{f}>0 \\
0, \text { otherwise }
\end{array},\right.
$$

the utility function for a person of gender $i=\{f, m\}$ who is married to a person from gender $j \neq i$, the momentary utility function reads

$$
U_{i}^{M}\left(c, l_{i}, l_{j}, q\right)=\log (c)-B l_{i}^{1+\frac{1}{\gamma}}-\frac{1}{2} \chi\left\{l_{f}\right\} q
$$


Note that consumption is a public good within the household. Note also that the parameter $\gamma>0$ is the intertemporal elasticity of labor supply and is independent of gender and marital status.

We assume that $q \in Q$, where $Q \subset R_{++}$is a finite set. We assume that for a given household, the distribution function for $q$ depends on labor market productivity of the husband. Let $\zeta(q \mid z)$ denote the probability that the cost of joint work is $q$, with $\sum_{q \in Q} \zeta(q \mid z)=1$ for all $z$, for a household with male productivity level $z$. This particular choice for $\zeta$ will become apparent when we discuss our calibration strategy in the next section. At the start of life, once a particular $(x, z)$ household is formed, the household draws its $q$, which remains constant until retirement. We assume that each member of the household incurs half of this total utility cost.

Production and Markets There are competitive firms that operate a constant returns to scale technology. Firms rent capital and labor services from households at the rate $R$ and $w$, respectively. Using $k$ units of capital and $l$ units of labor, firms produce $F(k, l)=k^{\alpha} l^{1-\alpha}$ units of consumption good. We assume that the capital depreciates at rate $\delta_{k}$.

Households save in the form of a risk-free asset that pays the competitive rate of return $r$. There are no markets to insure mortality or retirement risk. We assume that assets of agents who die are not distributed among those who survive.

Incomes and Taxation Let $a$ stand for household's assets. Then, the total pre-tax resources of a single working male are given by $a+r a+w z l$, whereas for a single female worker they amount to $a+a r+w x l$. The pre-tax total resources for a married working couple are given by $a+r a+w z l_{m}+w x l_{f}$. Let $b_{i}^{S}$ and $b^{M}$ indicate the level of social security benefits for singles, for $i=f, m$, and married retired households, respectively. Then, retired households' pre-tax resources are simply $a+r a+b_{i}^{S}$ for single retired households, and $a+r a+b^{M}$ for married ones.

Income for tax purposes, $I$, is defined as total labor and capital income; hence for a single male worker $I=r a+w z l$, while for a single female worker $I=r a+w x l$. For a married working household, taxable income equals $I=r a+w z l_{m}+w x l_{f}$. We assume that social security benefits are not taxed, so the income for tax purposes is simply given by $r a$ for retired households. The total income tax liabilities of married and single households are 
represented by tax functions $T^{M}(I)$ and $T^{S}(I)$, respectively. These functions are continuous in $I$, increasing and convex. There is also a (flat) payroll tax that taxes individual labor incomes, represented by $\tau_{p}$, to fund social security transfers. Besides the income and payroll taxes, each household pays an additional flat capital income tax for the returns from his/her asset holdings, denoted by $\tau_{k}$.

Demographics Let $M(x, z)$ denote the number of marriages between a type- $x$ female worker and a type- $z$ male worker, and let $\omega(z)$ and $\phi(x)$ denote the number of single type- $z$ male workers and the number of single type- $x$ female workers, respectively. Let $M^{r}(x, z)$, $\omega^{r}(z)$ and $\phi^{r}(x)$ denote the similar quantities for retirees. Then, the following two accounting identities

$$
\Phi(x) \equiv \sum_{z} M(x, z)+\phi(x)+\sum_{z} M^{r}(x, z)+\phi^{r}(x),
$$

and

$$
\Omega(z) \equiv \sum_{x} M(x, z)+\omega(z)+\sum_{x} M^{r}(x, z)+\omega^{r}(z),
$$

hold by construction. Agents who die (married or single) are replaced by identical young agents, who are born with no assets. This implies that every period, $\delta M^{r}(x, z)$ working married couples are born; the corresponding numbers for singles are $\delta \phi^{r}(x)$ and $\delta \omega^{r}(z)$.

Note that the law of motion for the number of retired married people reads

$$
M^{r \prime}(x, z)=\underbrace{(1-\delta) M^{r}(x, z)}_{\text {surviving retired couples }}+\underbrace{\rho M(x, z)}_{\text {newly retired couples }},
$$

which implies the following steady state condition:

$$
\delta M^{r}(x, z)=\rho M(x, z) .
$$

Therefore, in a steady state retired couples who die must be replaced by retiring couples of the same type. Similarly, for single retired males and females, the following steady state relations must hold

$$
\delta \phi^{r}(x)=\rho \phi(x),
$$

and

$$
\delta \omega^{r}(z)=\rho \omega(z) .
$$


Equations (6), (7) and (8) imply that the number of working agents, married and single, is constant over time. Using the steady state restrictions implied by equations (6), (7) and (8), we can rewrite equation (3) as

$$
\Phi(x)=\sum_{z} M(x, z)+\frac{\rho}{\delta} \sum_{z} M(x, z)+\phi(x)+\frac{\rho}{\delta} \phi(x) .
$$

This equation restricts how $\Phi(x), M(x, z)$, and $\phi(x)$ are related. Similarly, the steady state version of equation (4) is given by

$$
\Omega(z)=\sum_{x} M(x, z)+\frac{\rho}{\delta} \sum_{x} M(x, z)+\omega(z)+\frac{\rho}{\delta} \omega(z) .
$$

When we parameterize the model (see below), our strategy is to treat $\Phi(x), \Omega(z)$, and $M(x, z)$ as the primitives and select $\phi(x)$ and $\omega(z)$ to satisfy the stationarity assumption. Hence, these two equations allow us to pin down $\phi(x)$ and $\omega(z)$ given the data on $\Phi(x)$, $\Omega(z)$, and $M(x, z)$.

The Problem of a Single Household We now define problems of single and married households recursively. First, consider the problem of a retired single agent and without loss of generality focus on the problem of a single retired male with asset level $a$. A single retired male simply decides how much to save, $a^{\prime}$, and his problem is given by

$$
V_{m}^{S, r}(a)=\max _{a^{\prime} \geq 0}\left\{U^{s}(c, 0)+(1-\delta) \beta V_{m}^{S, r}\left(a^{\prime}\right)\right\}
$$

subject to

$$
c+a^{\prime}=a(1+r)+b_{m}^{S}-T^{S}(r a)-\tau_{k} r a .
$$

The value of being a single retired female with assets $a, V_{f}^{S, r}(a)$, is defined in a similar way. Let $a_{j}^{S, r}(a)$, for $j=\{f, m\}$, be the decision rules for retired single agents.

Consider now the problem of a single male worker of type $(z, a)$. A single worker of type$(z, a)$ decides how much to work and how much to save, taking into account the retirement probability, $\rho$. His problem is given by

$$
V_{m}^{S}(z, a)=\max _{a^{\prime}, l_{m}^{S}}\left\{U^{S}\left(c, l_{m}^{S}\right)+\beta\left[(1-\rho) V_{m}^{S}\left(z, a^{\prime}\right)+\rho V_{m}^{S, r}\left(a^{\prime}\right)\right]\right\}
$$

subject to

$$
c+a^{\prime}=a(1+r)+w z l_{m}^{S}\left(1-\tau_{p}\right)-T^{S}\left(w z l_{m}^{S}+r a\right)-\tau_{k} r a,
$$


and

$$
l_{m}^{S} \geq 0, a^{\prime} \geq 0
$$

The value of being a single female worker $V_{f}^{S}(x, a)$ can be defined in a similar fashion. Again, let $a_{f}^{S}(x, a)$ and $a_{m}^{S}(z, a)$ represent the savings decisions for single females and males, respectively, and let $l_{f}^{S}(x, a)$ and $l_{m}^{S}(z, a)$ be their labor supply decision rules.

The Problem of Married Households Again, consider first the problem of a retired couple with assets $a$. Their problem, with the associated decision rule $a^{M, r}(a)$, is given by

$$
V^{M, r}(a)=\max _{a^{\prime} \geq 0}\left\{U_{m}^{M}(c, 0,0, q)+U_{f}^{M}(c, 0,0, q)+(1-\delta) \beta V^{M, r}\left(a^{\prime}\right)\right\}
$$

subject to

$$
c+a^{\prime}=a(1+r)+b^{M}-T^{M}(r a)-\tau_{k} r a .
$$

Consider now the problem of a married working household of type $(x, z, a, q)$. A married working household solves a joint maximization problem by choosing consumption, nextperiod assets and labor supply for each household member. The problem is given by

$$
\begin{aligned}
V^{M}(x, z, a, q) & =\max _{a^{\prime}, l_{f}^{M}, l_{m}^{M}}\left\{\left[U_{m}^{M}\left(c, l_{m}^{M}, l_{f}^{M}, q\right)+U_{f}^{M}\left(c, l_{m}^{M}, l_{f}^{M}, q\right)\right]\right. \\
& \left.+\beta\left[(1-\rho) V^{M}\left(x, z, a^{\prime}, q\right)+\rho V^{M, r}\left(a^{\prime}\right)\right]\right\}
\end{aligned}
$$

subject to

$$
c+a^{\prime}=a(1+r)+w\left(z l_{m}^{M}+x l_{f}^{M}\right)\left(1-\tau_{p}\right)+r a-T^{M}\left(w z l_{m}^{M}+w x l_{f}^{M}+r a\right)-\tau_{k} r a
$$

and

$$
l_{m}^{M} \geq 0, \quad l_{f}^{M} \geq 0, \quad a^{\prime} \geq 0 .
$$

Like singles, a married couple decides how much to work and how much to save. Unlike singles, they might choose zero market hours for female member of the household. This will occur if $q$ is too high, given the productivity levels $x$ and $z$ and asset holdings $a$. Let $l_{f}^{M}(x, z, a, q), l_{m}^{M}(x, z, a, q)$, and $a^{M}(x, z, a, q)$ represent the optimal decision rules associated with this problem. 
Aggregate Consistency The aggregate state of this economy consists of distribution of households over their types and asset levels. Suppose $a \in A=[0, \bar{a}]$. Consider first workers. Let $\psi^{M}(B, x, z, q)$ be the number (measure) of working married households of type $(x, z, q)$, with assets $B \in \mathcal{A}$, the class of Borel subsets of $A$. Similarly, let $\psi_{f}^{S}(B, x)$ be the number of working single females of type $x$, with $a \in B$, and let $\psi_{m}^{S}(B, z)$ be the number of single working males of type $(z)$, with $a \in B$. By construction, $M(x, z)$, the number of married working households of type $(x, z)$, must satisfy

$$
M(x, z)=\sum_{q} \int_{A} \psi^{M}(a, x, z, q) d a .
$$

Similarly, the number of single households (agents) must be consistent with $\psi_{f}^{S}(x, a)$ and $\psi_{m}^{S}(z, a)$, i.e., $\phi(x)$ and $\omega(z)$ must satisfy

$$
\phi(x)=\int_{A} \psi_{f}^{S}(a, x) d a,
$$

and

$$
\omega(z)=\int_{A} \psi_{m}^{S}(a, z) d a .
$$

Since retired agents are not allowed to work, they only differ by their marital status and asset holdings. Let $\psi^{M, r}(B), \psi_{f}^{S, r}(B)$ and $\psi_{m}^{S, r}(B)$ denote the asset distribution among retired married, retired single female and retired single male households, respectively, with $a \in B$. Like their counterparts for workers, these distributions must be consistent with $M^{r}(x, z)$, $\phi^{r}(x)$ and $\omega^{r}(z)$.

Equilibrium In stationary equilibrium, factor markets clear, so aggregate capital $(K)$ and aggregate labor $(L)$ are given by

$$
\begin{aligned}
K= & \sum_{x, z, q} \int_{A} a \psi^{M}(a, x, z, q) d a+\sum_{z} \int_{A} a \psi_{m}^{S}(a, z) d a+\sum_{x} \int_{A} a \psi_{f}^{S}(a, x) d a \\
& +\int_{A} a \psi^{M, r}(a) d a+\int_{A} a \psi_{m}^{S, r}(a) d a+\int_{A} a \psi_{f}^{S, r}(a) d a
\end{aligned}
$$

and 


$$
\begin{aligned}
L= & \sum_{x, z, q} \int_{A}\left(x l_{f}^{M}(a, x, z, q)+z l_{m}^{M}(a, x, z, q)\right) \psi^{M}(a, x, z, q) d a+ \\
& \sum_{z} \int_{A} z l_{m}^{S}(a, z) \psi_{m}^{S}(a, z) d a+\sum_{x} \int_{A} x l_{f}^{S}(a, x) \psi_{f}^{S}(a, x) d a .
\end{aligned}
$$

In addition, factor prices are competitive so $w=F_{2}(K, L), R=F_{1}(K, L)$, and $r=R-\delta_{k}$. In the Appendix, we provide a formal definition of equilibria.

\section{Parameter Values}

We now proceed to assign parameter values to the endowment, preference and technology parameters of our benchmark economy. To this end, we use cross-sectional, aggregate as well as demographic data. As a first step in this process, we start by defining the length of a period to be a year.

Demographics and Endowments We assume that agents are workers for forty years, corresponding to ages 25 to 64 , and set $\rho=1 / 40$ accordingly. Absent population growth in the model, we set $\delta$ so that the model is consistent with the observed fraction of retired individuals (65 years and above), as a fraction of the population 25 years and older. From the 2000 Census, we calculate that this fraction was 0.203. Hence, given the value assumed for $\rho$, we set $\delta$ equal to 0.0982 in order to reproduce the same age structure in the benchmark economy.

We set the number of productivity types (labor endowments) to five. Each productivity type corresponds to an educational attainment level: less than high school $(<\mathrm{hs})$, high school (hs), some college (sc), college (col) and post-college education ( $>$ col). We use data from the Consumer Population Survey (CPS) to calculate efficiency levels for all types of agents. Efficiency levels correspond to mean hourly wage rates within an education group, which we construct using annual wage and salary income, weeks worked, and usual hours worked data. ${ }^{7}$ We include in the sample household heads and spouses between 25 and 54, and exclude those who are self-employed or unpaid workers. Table 1 shows the estimated efficiency levels for the corresponding types, where wage rates for each type and gender are

\footnotetext{
${ }^{7}$ We find the mean hourly wages as $\frac{\text { annual wage and salary income }}{\text { (usual hours worked)(number of weeks worked) }}$.
} 
normalized by the overall mean hourly wages in the sample. The table also reports the observed gender gap in hourly wage rates for each educational group; the gap is roughly constant across educational categories, averaging about $72 \%$.

We subsequently determine the distribution of individuals by productivity types for each gender, i.e., $\Omega(z)$ and $\Phi(x)$, using the 2000 Census. For this purpose, we assume an underlying stationary demographic data, and assume that the distribution of retired agents by educational attainment is the same as the observed distribution of agents prior to retirement. Given this assumption, we consider all household heads or spouses who are between ages 25 and 64 and for each gender calculate the fraction of population in each education cell. For the same age group, we also construct $M(x, z)$, the distribution of married working couples, as shown in Table 2. Consistent with positive assortative matching by education, the largest entries in each row and column in Table 2 are located along the diagonal. ${ }^{8}$

Finally, given the fractions of individuals in each education group, $\Phi(x)$ and $\Omega(z)$, and the fractions of married working households, $M(x, z)$, in the data, we calculate the implied fractions of single working households, $\omega(z)$ and $\phi(x)$, reported in Table 3. About $74 \%$ of households in the benchmark economy consist of married households, while the rest (about $26 \%)$ are single-person ones. This table also shows $\omega(z)$ and $\phi(x)$ that we construct from the 2000 Census. The mismatch between implied and actual values of $\omega(z)$ and $\phi(x)$ is quite small, suggesting that stationary population structure is not an unrealistic assumption.

Technology We specify the production function as Cobb-Douglas with capital share equal to 0.317. In the absence of population growth and growth in labor efficiency, we set the depreciation rate equal to 0.07 . These values are consistent with a notion of capital that excludes residential capital, consumer durables and government owned capital for the period 1960-2000. The corresponding notion of output is then GDP accounted for by the business sector. Altogether, this implies a capital to output ratio of about $2.325 .{ }^{9}$

Taxation To construct income tax functions for married and single individuals, we estimate effective taxes paid by married and single households as a function of their reported

\footnotetext{
${ }^{8}$ See Fernández, Guner and Knowles (2005) for a recent theoretical and empirical study of positive assortative matching by education.

${ }^{9}$ See Guner, Ventura and Xu (forthcoming) for details.
} 
income. We use tabulated data from the Internal Revenue Service by income brackets. ${ }^{10}$ For each income bracket, total income taxes paid, total income earned, number of taxable returns and number of returns data are publicly available. Using these, we find the mean income and the average tax rate corresponding to every income bracket. We calculate the average tax rates as

$$
\text { average tax rate }=\frac{\left\{\frac{\text { total amount of income tax paid }}{\text { number of taxable returns }}\right\}}{\left\{\frac{\text { total adjusted gross income }}{\text { number of returns }}\right\}} .
$$

Following Gouveia and Strauss (1994), we then estimate the effective tax functions for both married and single households. In particular, we fit the following equation to the data:

$$
\text { average tax rate }(\text { income })=\eta_{1}+\eta_{2} \log (\text { income })+\varepsilon \text {, }
$$

where average tax (income) is the average tax rate that applies when average income in an income bracket equals income. We calculate income by normalizing average income in each income bracket by the mean household income in 2000. Table 4 shows the estimates of the coefficients for married and single households.

Given these estimates, we specify the tax functions in the benchmark model as

$$
T^{M}(\text { income })=[0.1023+0.0733 \log (\text { income })] \text { income },
$$

and

$$
T^{S}(\text { income })=[0.1547+0.0497 \log (\text { income })] \text { income } .
$$

Figures 2 and 3 display estimated average and marginal tax rates for different multiples of household income. Our estimates imply that a single person with twice mean household income in 2000 faces an average tax rate of about $18.9 \%$ and a marginal tax rate equal to about $23.9 \%$. The corresponding rates for a married household with the same income are about $15.3 \%$ and $22.6 \%$.

Finally, we need to assign a value for the (flat) capital income tax rate $\tau_{k}$, which we use to proxy the corporate income tax. We estimate this tax rate as the one that reproduces the observed level of tax collections out of corporate income taxes after the major reforms of 1986. For the period 1987-2000, such tax collections averaged about $1.92 \%$ of GDP. Using the technology parameters we calibrate in conjunction with our notion of output (business

\footnotetext{
${ }^{10}$ Source: Internal Revenue Service (2000), Statistic of Income Division, Individual Income Tax Returns Bulletin (Publication 1304). See Kaygusuz (2006a) for further details.
} 
GDP), we obtain $\tau_{k}=0.124$. In the benchmark economy, income taxes plus the additional tax on capital, amount to $13.1 \%$ of aggregate output.

Social Security We calculate $\tau_{p}=0.086$ as the average value of the social security contributions as a fraction of aggregate labor income for the $1990-2000$ period. ${ }^{11}$ Using Social Security Beneficiary Data, we calculate that during this same period a retired single woman obtained old-age benefits of about 0.77 of a single retired male, while a retired couple averaged benefits of about 1.5 times those of a retired single male. Thus, given the payroll tax rate, the value of the benefit for a single retired male, $b_{m}^{S}$, balances the budget for the social security system.

Preferences There are two utility functions parameters, the intertemporal elasticity of labor supply $(\gamma)$ and the parameter governing the disutility of market work $(B)$. We consider two values for $\gamma$ : a low value of 0.2 and a higher value of 0.4 . Both values are consistent with recent estimates for males. While $\gamma=0.2$ is in line with microeconomic evidence reviewed by Blundell and MaCurdy (1999), $\gamma=0.4$ is contained in the range of recent estimates by Domeij and Floden (2006, Table 5). The results of Domeij and Floden (2006) are based upon estimates for married males that control for the bias emerging from borrowing constraints. ${ }^{12}$ We proceed by presenting first results when the intertemporal elasticity of substitution equals 0.4. In subsequent sections, we discuss the implications of a lower value for this parameter. Given $\gamma$, we select the parameter $B$ to reproduce average market hours per worker observed in the data. These average hours per worker amounted to about $40.8 \%$ of available time in $2000 .^{13}$

We assume that the utility cost parameter is distributed according to a (flexible) gamma distribution, with parameters $k_{z}$ and $\theta_{z}$. Thus, conditional on the husband's type $z$,

\footnotetext{
${ }^{11}$ The contributions considered are those from the Old Age, Survivors and DI programs. The Data come from the Social Security Bulletin, Annual Statistical Supplement, 2005, Tables 4.A.3.

${ }^{12}$ Rupert, Rogerson and Wright (2000) provide estimates within a similar range in the presence of a home production margin. Heathcote, Storesletten and Violante (2007) report an estimate of 0.2, using a model with incomplete markets.

${ }^{13}$ The numbers are for people between ages 25 and 54 and are based on data from the Consumer Population Survey. We find mean yearly hours worked by all males and females by multiplying usual hours worked in a week and number of weeks worked. Married males work 2294 hours per year, and married females work 1741 hours per year. We assume that each person has an available time of 5000 hours per year. Our target for hours corresponds to 2040 hours per year.
} 


$$
q \sim \zeta(q \mid z) \equiv q^{k_{z}-1} \frac{\exp \left(-q / \theta_{z}\right)}{\Gamma\left(k_{z}\right) \theta_{z}^{k_{z}}},
$$

where $\Gamma($.$) is the gamma function. By proceeding in this way, we exploit the information$ contained in the changes in the labor force participation of married females as their own wage rate increases with education (for a given husband type). We emphasize that this allows us to control the slope of the distribution of utility costs. As we argued in section 2, the shape of the distribution of utility costs is potentially critical in assessing the effects of tax changes on labor force participation.

Using CPS data, we calculate the employment-population ratio of married females between ages 25 and 54, for each of the educational categories defined earlier. ${ }^{14}$ Table 5 shows the resulting distribution of the labor force participation of married females by the productivities of husbands and wives for married households. The aggregate labor force participation for this group is $69.4 \%$, and it increases from $44.8 \%$ for the lowest education group to $82.5 \%$ for the highest. Our strategy is then to select the two parameters governing the gamma distribution, for every husband type, so as to reproduce each of the rows (five entries) in Table 5 as closely as possible. Altogether, this process requires estimating 10 parameters (i.e., a pair $(\theta, k)$ for each husband educational category).

It is important to note that selecting a particular $\zeta(q \mid z)$ function restricts the elasticities of female labor supply along the extensive margin. Tables 1 and 5 allow us to calculate these elasticities in a straightforward manner. Take, for example, females who are married to males with some college education and compare those with some college education to ones with college education. The labor force participation rises by about $10.6 \%$ while the wages increase by about 32\%, implying an elasticity of labor force participation of about 0.34. If we repeat the same exercise for women with college and with post college education, the implied elasticity turns out to be about 0.28. Similar calculations can be repeated for any two adjacent entries of a particular row in Table 5. These elasticities range from 0.1 (comparing women with college and with post college education who are married to men with high school education) to 1.6 (comparing women with less than high school and with high school education who are married to men with less than high school education), while for the bulk of the population they are on the order of 0.3-0.5. These elasticities are well within the

\footnotetext{
${ }^{14}$ We consider all individuals who are not in the armed forces.
} 
available empirical estimates. Eissa (1995), using 1986 tax reform as a natural experiment, estimates an elasticity with respect to the after-tax wage of approximately 0.8 and claims that at least half of the responsiveness is on the participation margin. Triest (1990) estimates uncompensated wage elasticities for married women on the order of 0.86-1.12, and suggests that almost all action comes from the extensive margin.

Finally, we choose the remaining preference parameter, the discount factor $\beta$, so that the steady-state capital to output ratio matches the value in the data consistent with our choice of the technology parameters (2.325). Table 6 summarizes our parameter choices. Table 7 shows the performance of the benchmark model in terms of the targets we impose for $B$ and $\beta$, i.e., labor hours per worker and capital output ratio. The table also shows how well the benchmark calibration matches the labor force participation of married females. Although, as we explained above, our calibration strategy is to match each row of Table 5, it is more instructive to look at the aggregate participation rate of married females and the labor force participation of married females by their educational level. The model has no problem in reproducing jointly these observations as the table demonstrates.

\section{Tax Reforms}

We now consider four hypothetical reforms to the current U.S. tax structure: a proportional consumption tax, a proportional income tax, a progressive consumption tax, and a move from joint to separate filing for married couples. The first reform flattens the current income tax schedule and changes the tax base from income to consumption, effectively eliminating the taxation of capital income built into the income tax. The second reform only flattens the tax schedule while keeping income as the tax base. The third reform reintroduces progressivity into a consumption tax system. Finally, the last reform changes the unit of taxation from households to individuals.

The findings we report are based on steady state comparisons of pre and post-reform economies. In all reforms, we keep the additional tax rate on capital income $\left(\tau_{k}\right)$ and the social security system unchanged. ${ }^{15}$ The exercises are in all cases revenue neutral.

\footnotetext{
${ }^{15}$ Results when the tax rate on capital income is also eliminated are available upon request.
} 
A Proportional Consumption Tax The first reform replaces current income taxes with a proportional consumption tax, which makes marginal and average tax rates equal for all households. For a better understanding of the results, the reader should bear in mind that a consumption tax still distorts labor choices, but by construction eliminates the distortions on capital accumulation created by the income tax.

Table 8 reports key findings from this exercise. In line with the existing literature, the effects of a consumption tax on aggregates are dramatic. Aggregate output increases by about $11.2 \%$. As a result, a flat consumption tax of $17.8 \%$ is all that is needed to generate revenue neutrality. The long-run rise in output is fueled by significant rises in factor inputs. The capital-to-output ratio increases by about $15 \%$ in the post-reform steady state. Total (raw) hours in turn increase by $4.7 \%$, while labor supply (hours adjusted by efficiency units) increases by $4.2 \%$. Despite the rise in labor supply, as a result of the higher capital stock in post-reform economy, the wage rate increases by $6.5 \%$ as well.

Our economy allows us to identify and quantify differential responses in labor supply to tax changes that take place at the intensive margin for both males and females, as well as at the extensive margin for married females. Recall that in the benchmark economy, the tax structure generates non-trivial disincentives to work since marginal tax rates increase with incomes. In particular, married females who decide to enter the labor force are taxed at their partner's current marginal tax rate. With the elimination of these disincentives, in conjunction with the partial removal of capital income taxation, the change in labor supply of married females is substantially larger than the aggregate change in hours. The introduction of a consumption tax implies that the labor force participation of married females increases by $7.3 \%$, while hours per worker rise by about $2.6 \%$ for females, and about $2.8 \%$ for males. Due to changes along the intensive and the extensive margin, total hours for married females increase by about $10.6 \%$. This is a dramatic rise and is more than three times the change in total male hours. These results are especially worth noting as the parameter governing intertemporal substitution of labor is the same for males and females.

A Proportional Income Tax The second reform is similar to the first one but introduces a proportional income tax instead of a proportional consumption tax. The consequences of this reform could then be viewed as the consequences of simply flattening out the current income tax schedule. 
The key finding from this exercise is that the resulting rise in labor supply is smaller but similar to the one in the consumption tax case, $4.7 \%$ versus $4.3 \%$. This suggests that the main contribution to changes in the labor input comes from the flattening of the tax schedule. Hours per workers for males and females increase by about $2.6 \%$ and $2.3 \%$, respectively, and total hours increase by about $4.3 \%$. Again, the rise in total hours by married females is very pronounced, of about $9.3 \%$, and again more than three times the change in total male hours.

In relation to the case with a proportional consumption tax, the effects on capital accumulation are now less pronounced. This is expected: an income tax, differently from a consumption tax, still distorts asset accumulation decisions. Consequently, the capital-tooutput ratio increases by just $4.5 \%$. Overall, as a result of smaller rises in both labor and capital inputs, the effects on aggregate output (although still substantial) are smaller than under a proportional consumption tax. In the current case the change in output amounts to about $5.9 \%$, whereas under proportional consumption taxes the effects are almost twice as big: $11.2 \%$.

A Progressive Consumption Tax In our third exercise we consider a progressive consumption tax, which consists of an exemption level below which households do not pay taxes, and a proportional tax on household consumption applied above this level. To illustrate the consequences of different exemption levels, we consider a "high" exemption case and a "low" exemption case. The "high exemption amounts to $1 / 3$ of mean consumption in our benchmark economy for single households, and $1 / 2$ of mean consumption in our benchmark economy for married ones. The 'low' exemption equals $1 / 4$ of mean consumption in our benchmark economy for married households, and 1/6 of aggregate consumption in our benchmark economy for single ones. ${ }^{16}$ We emphasize that these exemption levels are defined as multiples of consumption in the benchmark case; as a result, they do not vary when consumption changes (increases) as a result of the reform in question.

Results are reported in Table 9. Under a high exemption, the reform requires a tax rate of $27.5 \%$, whereas under a low exemption the required rate is $21.5 \%$; the corresponding rate under a proportional consumption tax was 17.8\%. A comparison between proportional and progressive consumption tax reforms (Tables 8 and 9) is quite revealing. The effects on

\footnotetext{
${ }^{16}$ In 2005 , consumption per-person 25 years old and above was about $\$ 45,110$. Thus, the value of the high (low) exemption for a married couple is approximately $\$ 22,555(\$ 11,253)$.
} 
capital intensity are comparable under both types of reforms. This should not be surprising since the bulk of capital is owned by households who are above the exemption levels and they are affected in a similar way in these reforms; both reforms eliminate the distorting effects of income taxes on their asset accumulation decisions. The effect on aggregate output in the long run, however, is now lower than under a proportional consumption tax and declines steeply with increases in exemption levels. This is clearly due to the smaller increases in the labor input. Note that hours and the labor input increase by about $1.5 \%$ with the high exemption level and 3.6-3.2\% with the low one, whereas the increase was about $4.7 \%$ and $4.2 \%$, respectively, under a proportional consumption tax.

It is important to understand the channels that lead to a much smaller rise in aggregate labor under a progressive consumption tax than under a proportional one. We start by noting that for households at the top of the skill distribution and therefore above the exemption threshold, the relevant marginal tax distorting labor choices is larger than under a proportional consumption tax. This high marginal tax rate, in conjunction with the implicit transfer associated to a progressive tax, results in a lower response from these households in terms of work hours. In turn, the effect on households at the top has an important effect on aggregate labor in efficiency units, as these households have a disproportionate contribution to this variable. A progressive consumption tax reform also discourages labor supply at the bottom of skill distribution as these households have incentives to stay below the exemption level. These phenomena are present in previous studies with heterogeneity, such as Altig et al (2001), Conesa and Krueger (2006), Nishiyama and Smetters (2005) and Ventura (1999).

The current framework, however, allows us to uncover the differential effects of a progressive consumption tax on the labor force participation of married females. Consider first the case of high exemption level. The rise in labor force participation in this case is less than half of the rise under a proportional consumption tax (3.2\% versus $7.3 \%)$. This is a central result regarding the expected effects of a tax reform of this sort. The key for this finding is the structure of progressive consumption tax, which combines an exemption level and a common marginal tax rate above it. The interplay of these features discourages changes in labor force participation in married households with relatively less skilled members. When females in such households enter the labor force, some of these households face a positive (rather than zero) marginal tax rate. Therefore, the bulk of them choose not to enter the labor force. It turns out that these households were the ones that respond the most under 
proportional tax reforms; as we discuss in detail below. When we lower the exemption level, the number of households that face this trade-off becomes smaller, and the results look more similar to the ones obtained under a proportional consumption tax reform.

Separate Filing A common critique of the current U.S. tax system is that it treats married and single individuals differently. The problem arises since the unit subject to taxation is the household, not the individual, with tax schedules that differ according to marital status. This creates much discussed marriage-tax penalties and bonuses, affecting the marginal tax rates that married individuals face. In particular, note that when a married female enters the labor market the first dollar of her earned income is taxed at her husband's current marginal rate, potentially distorting her labor supply in a critical way. This reasoning motivates our final experiment, where we move from the current system to one in which each individual files his/her taxes separately, or separate filing. We assume that all individuals, married and single, face the same tax schedule, the one faced by singles in the benchmark economy, $T^{S}($.$) , and assume that a married person's tax liabilities consists of his/her labor$ income plus half of household's asset income. In addition, in order to collect the same amount of tax revenue as the benchmark economy, we assume that each individual faces an additional proportional tax (or subsidy) on his/her income. ${ }^{17}$

Given Figures 3, the move from $T^{M}($.$) to T^{S}($.$) would have a relatively small effect on$ marginal tax rates. The possibility of separate filing, however, can lower taxes on married females significantly. Consider a household with total income in the economy equal to twice mean household income, and suppose earnings of both members are equal. Under the current system, this household faces a marginal tax rate of about $23 \%$. The marginal tax rate declines to less than $20 \%$ if the household income is split equally between husband and wife. The gain is larger for the majority of wives who make less than their husbands.

The effects of a move from the current system to separate filing are substantial. Table 9 shows that aggregate output goes up by about 2.6\%. This is almost half of the increase associated with a proportional income tax reform. In contrast to other reforms, the increase in aggregate output comes almost fully from the rise in aggregate hours by married females. The labor force participation of married females rises by $5.9 \%$ (almost as much as it does with a proportional income and consumption taxes), and aggregate hours by married females

\footnotetext{
${ }^{17}$ It turns out that a subsidy of $1.5 \%$ is needed to achieve revenue-neutrality.
} 
increase by $7.3 \%$. In contrast, hours by male workers are nearly constant. The main message from this experiment is quite clear. A move from the current system to one in which individuals (not households) are the basic unit of taxation goes a long way in generating significant effects on aggregate labor and output. Note that this occurs without eliminating tax progressivity, or the taxation of capital income.

Discussion The analysis so far reveals several important insights that a single-agent framework would fail to capture. Notice that female labor force participation plays a significant role in all of the reforms we have considered. Under proportional taxes, the overall rise in married female hours is more than three times the rise in male hours, and fueled by a significant increase in the extensive margin. Furthermore, the structure of reforms interacts in a nontrivial way with the labor force participation of married females. The increases in the labor force participation, as well as aggregate hours of married females, under a progressive consumption tax reform can be much lower than those under a proportional consumption tax reform. Overall, these findings motivate us to explicitly quantify the relative importance of married females for our results. We do this in the next section.

\section{The Role of Married Females}

We now discuss in detail the changes in labor supply of married females. We ask: What is the overall contribution of married females to changes in labor supply? What is the importance of labor supply changes along the extensive margin?

In answering these questions, we first note that the type of tax reform under consideration is critical. Although the aggregate effects on labor supply are smaller under progressive consumption tax relative to a proportional one, the rise in married females' labor supply becomes a much more important component of the overall rise in labor supply (i.e., labor in efficiency units). Furthermore, the role of married females is largest with a move to separate filing. Table 10 makes these points clear. In this table we report the contribution of married females to changes in total hours and total labor supply under our benchmark calibration. For proportional consumption and income taxes, the contribution of married females to changes in total hours is around 58-59\%. Nevertheless, the contribution of married females to changes in total hours is much higher under a progressive consumption tax: about 
$65 \%$ and $80 \%$ for the low and high exemption values, respectively. This occurs as changes in labor supply for other groups are of smaller or negative magnitude under a progressive consumption tax. ${ }^{18}$ Married females' contributions are largest in separate filing reform; they contribute to more than $90 \%$ of changes in total hours. The contributions of married females to total labor supply follow a similar pattern, but the magnitudes are smaller. This occurs since females on average are less skilled than men, and since the rise in female labor supply is concentrated among low skilled ones, an issue that we elaborate below. The results in Table 10 indicate that married females account for about 49-50\% of the changes in labor supply under proportional taxes, about $55 \%$ and $65 \%$ of the changes under a progressive consumption tax, and almost about $90 \%$ under separate filing. We conclude that the overall contribution of married females is substantial; they contribute disproportionately to changes in labor supply given their share of the working age population (about 37.5\%).

In the bottom panel of Table 10 we focus on the role of the extensive margin and report its contribution to the rise in hours and total labor supply. In order to calculate the role of extensive margin, we count both the hours worked by married females who enter the labor market, as well as by those who stop participating. The latter is necessary as some married females, in particular those with low skills after a progressive consumption tax reform, prefer not to work in the post-reform economy. Concretely, for each $(x, z, a, q)$-type married woman, we first determine if labor force participation for this type is different between pre and post reform economies. If the change in participation is positive and a married woman enters the labor force after a reform, we weigh the change in participation by the hours she works (or the total labor she supplies) under the new tax system. Summing up over all such households gives us the total rise in hours (or in labor supply) due to extensive margin. If, on the other hand, the change is negative and a married woman stops working, we weigh the change in participation by the hours she worked (or total labor she supplied) in the benchmark economy. The difference between these two sums gives us the net change in hours (or total labor supply) due to the extensive margin. Using this measure, the extensive margin contributes about $49-51 \%$ of the changes in total hours under proportional taxes, about $57 \%$ and $71 \%$ of the changes under progressive taxes, and about $77 \%$ under separate

\footnotetext{
${ }^{18}$ The interplay of high marginal tax rates and an exemption value dictates that the bulk of single individuals decrease hours worked after the reform in the high exemption case. For single females, only those with college education increase hours $(0.2 \%)$. For single males, an increase in hours takes place for those with college education or above ( $0.6 \%$ and $0.8 \%$, respectively).
} 
filing. For changes in labor supply, the contributions are $41-43 \%$, about $47 \%$ and $55 \%$, and about $82 \%$, respectively. By this measure, these calculations suggest that the bulk of the rise in the labor supply of married females can be attributed to movements in the extensive margin.

A central finding emerging from our proportional tax exercises is that the increase in labor force participation of married females becomes larger as we move towards the bottom of the distribution of skills. Table 11 illustrates this point. In the table, households are arranged according to the skill type of the female member (from high school education or less to post-college education), and the resulting change in the labor force participation of married females is displayed. Both with a proportional consumption tax and a proportional income tax, the rise in female labor force participation for the lowest educational category is remarkable. These females increase their labor force participation by $22.5 \%$ under a proportional consumption tax system and by nearly $20 \%$ under a proportional income tax system. Under both reforms, the percentage increase in labor force participation decreases monotonically: from about $22.5 \%$ to about $2.7 \%$ under a proportional consumption tax and from about $20 \%$ to about $1.7 \%$ under a proportional income tax. A very similar pattern emerges in separate filing reform. Thus, the bulk of the changes along the extensive margin takes place in households with relatively less skilled members.

The results with a progressive consumption tax are different. With the high exemption level, the labor force participation of the lowest skill types is only about $1 \%$ higher than in the benchmark economy. The behavior of married females is affected significantly here: a higher labor force participation can move these households above the exemption threshold and change their marginal tax rate from zero to about $21.5 \%$ and $27.5 \%$. This clearly generates disincentives for labor force participation. Once we move to households with a female member who has more than high school education, the pattern is similar to what we observe with proportional income or consumption taxes. With the low exemption level, as the number of married households below the threshold is reduced, the results are similar to ones obtained by the proportional consumption tax reform. 


\section{The Importance of the Intertemporal Elasticity}

We now turn our attention to the role of the preference parameter $\gamma$ : the micro intertemporal elasticity of labor supply. For these purposes, we report results for the value on the low side of the empirical estimates for this parameter $(\gamma=0.2)$, and calibrate the rest of the parameters following the procedure discussed in Section 4. In particular, we recover new parameters for the distribution of utility costs so as to reproduce the facts on labor force participation.

Our results are summarized in Table 12. The key finding is that the importance of married females for the aggregate effects of tax reforms increases. As the table demonstrates, the contribution of married females to changes in labor hours and labor supply substantially goes up. For instance, the contribution to changes in hours now ranges from about $76 \%$ to $98 \%$ across experiments, while under the higher value, $\gamma=0.4$, the contribution ranged from $50 \%$ to $92 \%$.

These results are driven by the behavior of labor force participation under the low elasticity value. Note that changes in hours per worker are much smaller than under $\gamma=0.4$, but changes in labor force participation are larger. Since adjusting along the intensive margin is costlier with a low $\gamma$, married households find it optimal to adjust hours worked largely

along the extensive margin. This, in conjunction with the fact that the model under $\gamma=0.2$ has still to respect the underlying data on labor force participation, renders the substantial response of married females displayed in Table 12. In other words, a lower value of the labor supply elasticity implies a higher aggregate labor supply response from married females in tax reforms.

An implication of these findings on labor supply is that the impact of reforms on the size of the labor hours is not too different across the two values of $\gamma$. To illustrate this phenomenon, note first the behavior of male per-worker hours under a consumption tax: they change by about $2.8 \%$ with $\gamma=0.4$, and just by $1.4 \%$ with $\gamma=0.2$. Total hours, in contrast, change by an almost equal amount with both values of $\gamma$ (about $4.7 \%$ and $4.6 \%$ ). We conclude from these exercises that the precise value for this parameter is of second-order importance for understanding the aggregate effects of tax reforms on labor supply. 


\section{Comparisons with a Standard Macro Framework}

How do our results compare to those emerging from the standard macroeconomic setup with heterogeneous agents? To answer this question, we consider an economy with only single earner households, and eliminate all gender-based differences in wage rates and social security transfers. We use data on males to calibrate wage rates and the relative sizes of productivity groups, and impose the tax functions pertaining to married households. Altogether, these assumptions render a macroeconomic model with heterogenous agents consistent with those in the literature; e.g., Conesa and Krueger (2006) and Ventura (1999).

Results are displayed in Table 13 in the case of a consumption tax, for two values of the elasticity $\gamma$. The results show that for the high value of $\gamma$, the standard framework captures only about $89 \%$ of the output gains under the current framework, and about $83 \%$ of the changes in aggregate labor supply. For the low value of $\gamma$, not surprisingly, the fraction captured by the standard framework of output is smaller, and substantially smaller for the case of labor supply; about $85 \%$ and $51 \%$, respectively. It is worth noting that these results are obtained even when male hours respond more in the standard framework than in the current one. This follows as in the current framework, married households adjust labor supply of both spouses.

An important implication from these findings is that tax reform exercises can be misleading if a "standard" framework is used with low labor supply elasticities. The results in Table 13 provide a careful, model-based and quantitative argument for the use of high labor supply elasticities in the context of tax reforms.

\section{Concluding Remarks}

In this paper we study the aggregate effects of tax reforms for the US economy, taking seriously into account the labor supply decisions of married females and the underlying structure of household heterogeneity. For these purposes, and differently from the existing literature, our model economy consists of one and two-earner households, where two-earner households face explicit labor supply decisions along both intensive and extensive margins.

We find that tax changes can lead to large effects across steady states on aggregate variables. We explicitly quantify the relative importance of changes in the labor supply of 
different groups, and find that married females play a critical role in these changes. We find that when current taxes are replaced by proportional taxes, married females account for around 58-59\% of the total increase in labor hours, and about 49-50\% of the aggregate increase in labor in efficiency units. When current taxes are replaced by progressive consumption taxes, married females contribute even more to changes in hours and labor supply depending on the exemption value $(65 \%$ and $55 \%$ in the low case, and $80 \%$ and $65 \%$ in the high). Finally, when the current tax system is replaced with one that taxes individuals, not households, the rise in aggregate labor supply almost entirely comes from married females. We also calculate that the bulk of the changes accounted for by married females can be attributed to movements along the extensive margin.

We also find that when preferences are consistent with a labor supply elasticity on the low side of available estimates, the labor supply behavior of married females becomes even more important. In this case, married females account for at least three fourths of the changes in hours in a tax reform, as households adjust work hours largely by movements along the extensive margin. We conclude from these exercises that the value of this preference parameter is of second-order importance in understanding the effects on output and labor supply associated to tax reforms. Finally, reforms in a standard version of the model, populated only by single agents, result in output gains that are up to $15 \%$ lower than our benchmark economy.

Our results have serious implications for policy. One of these implications relates to the interplay between distorting taxes and other non-tax barriers to female labor force participation. Such barriers include the restrictive regulation of temporary work, and product market distortions such as restrictions on shopping hours, that are common in several developed economies. If married females drive the bulk of hour changes associated to tax reforms, these obstacles to increasing participation can interact with changes in the tax structure, and prevent the large predicted changes in labor supply to materialize. From this perspective, a more complete analysis of taxation and labor supply should study these issues. We leave this and other extensions for future work. 


\subsection{Appendix: Definition of Equilibrium}

Let $\psi^{M}(B, x, z, q)$ denote the number of married individuals with assets $a \in B$, when the female is of type $x$, the male is of type $z$, and the household faces a utility cost $q$ of joint work. This function (measure) is defined for all Borel sets $B \in \mathcal{A}$, all $x, z, q \in X \times Z \times Q$. The measures $\psi_{f}^{S}(B, x)$ (single females), $\psi_{m}^{S}(B, z)$ (single males), $\psi^{M, r}(B)$ (retired married couples), $\psi_{f}^{S, r}(B, x)$ (retired single females) and $\psi_{m}^{S, r}(B, x)$ (retired single males) are defined in similar way.

Let $\chi\{$.$\} denote the indicator function. The measures defined above obey the following$ recursions:

Married working agents:

$$
\begin{aligned}
\psi^{M}(B, x, z, q) & =(1-\rho) \int \psi^{M}(a, x, z, q) \chi\left\{a^{M}(a, x, z, q) \in B\right\} d a \\
& +\delta M^{r}(x, z) \zeta(q \mid z) \chi\{0 \in B\}
\end{aligned}
$$

Single working agents:

$$
\begin{gathered}
\psi_{f}^{S}(B, x)=(1-\rho) \int \psi_{f}^{S}(a, x) \chi\left\{a_{f}^{S}(a, x) \in B\right\} d a+\delta \phi^{r}(x) \chi\left(a^{\prime}\right) \chi\{0 \in B\} \\
\psi_{m}^{S}(B, z)=(1-\rho) \int \psi_{m}^{S}(a, z) \chi\left\{a_{m}^{S}(a, x) \in B\right\} d a+\delta \omega^{r}(x) \chi\{0 \in B\} .
\end{gathered}
$$

$\underline{\text { Married retired agents: }}$

$\psi^{M, r}(B)=(1-\delta) \int \psi^{M, r}(a) \chi\left\{a^{M, r}(a) \in B\right\} d a+\rho \sum_{x, z, q} \int \psi^{M}(a, x, z, q) \chi\left\{a^{M}(a, x, z, q) \in B\right\} d a$

$\underline{\text { Single retired agents: }}$

$$
\begin{aligned}
& \psi_{f}^{S, r}(B)=(1-\delta) \int \psi_{f}^{S, r}(a) \chi\left\{a_{f}^{S, r}(a) \in B\right\} d a+\rho \sum_{x} \int \psi_{f}^{S}(x, a) \chi\left\{a_{f}^{S}(a, x) \in B\right\} d a, \\
& \psi_{m}^{S, r}(B)=(1-\delta) \int \psi_{m}^{S, r}(a) \chi\left\{a_{m}^{S, r}(a) \in B\right\} d a+\rho \sum_{z} \int \psi_{m}^{S}(a, z) \chi\left\{a_{m}^{S}(a, z) \in B\right\} d a .
\end{aligned}
$$


Equilibrium Definition: For a given government consumption level $G$, social security tax benefits $b^{M}, b_{f}^{S}$ and $b_{m}^{S}$, tax functions $T^{S}(),. T^{M}($.$) , a payroll tax rate \tau_{p}$, a capital tax rate $\tau_{k}$, and an exogenous demographic structure represented by $\Omega(z), \Phi(x), M(x, z)$, a stationary equilibrium consists of prices $r$ and $w$, aggregate capital $(K)$ and labor $(L)$, household decision rules $l_{f}^{M}(a, x, z, q), l_{m}^{M}(a, x, z, q), l_{m}^{S}(a, z), l_{f}^{S}(a, x), a^{M}(a, x, z, q), a_{m}^{S}(a, z)$, $a_{f}^{S}(a, x), a^{M, r}(a), a_{m}^{S, r}(a)$, and $a_{f}^{S, r}(a)$, and measures $\psi^{M}, \psi_{f}^{S}, \psi_{m}^{S}, \psi^{M, r}, \psi_{f}^{S, r}$ and $\psi_{m}^{S, r}$ such that

1. Given tax rules and factor prices, the decision rules of households are optimal.

2. Factor prices are competitively determined; i.e. $w=F_{2}(K, L)$, and $r=F_{1}(K, L)-\delta_{k}$.

3. Factor markets clear; i.e.,

$$
\begin{aligned}
K= & \sum_{x, z, q} \int_{A} a \psi^{M}(a, x, z, q) d a+\sum_{z} \int_{A} a \psi_{m}^{S}(a, z) d a+\sum_{x} \int_{A} a \psi_{f}^{S}(a, x) d a \\
& +\int_{A} a \psi^{M, r}(a) d a+\int_{A} a \psi_{m}^{S, r}(a) d a+\int_{A} a \psi_{f}^{S, r}(a) d a \\
L= & \sum_{x, z, q} \int_{A}\left(x l_{f}^{M}(a, x, z, q)+z l_{m}^{M}(a, x, z, q)\right) \psi^{M}(a, x, z, q) d a+ \\
& \sum_{z} \int_{A} z l_{m}^{S}(a, z) \psi_{m}^{S}(a, z) d a+\sum_{x} \int_{A} x l_{f}^{S}(a, x) \psi_{f}^{S}(a, x) d a .
\end{aligned}
$$

4. The measures $\psi^{M}, \psi_{f}^{S}, \psi_{m}^{S}, \psi^{M, r}, \psi_{f}^{S, r}$ and $\psi_{m}^{S, r}$ are consistent with individual decisions.

5. The Government Budget and Social Security Budgets are Balanced; i.e.,

$$
\begin{aligned}
& G=\sum_{x, z, q} \int_{A} T^{M}(.) \psi^{M}(a, x, z, q) d a+\sum_{z} \int_{A} T^{S}(.) \psi_{m}^{S}(a, z) d a \\
&+\sum_{x} \int_{A} T^{S}(.) \psi_{f}^{S}(a, x) d a+\tau_{k} K \\
& \int_{A} b^{M} \psi^{M, r}(a) d a+\int_{A} b_{f}^{S} \psi_{f}^{S, r}(a) d a+\int_{A} b_{m}^{S} \psi_{m}^{S, r}(a) d a=\tau_{p} w L
\end{aligned}
$$


Table 1: Productivity Levels, by Type, by Gender

\begin{tabular}{cccc}
\hline \hline & Males $(z)$ & Females $(x)$ & $x / z$ \\
\cline { 2 - 4 }$<\mathrm{hs}$ & 0.709 & 0.505 & 0.712 \\
$\mathrm{hs}$ & 0.920 & 0.669 & 0.727 \\
$\mathrm{sc}$ & 1.113 & 0.799 & 0.718 \\
$\mathrm{col}$ & 1.447 & 1.052 & 0.727 \\
$>$ col & 1.809 & 1.326 & 0.733 \\
\hline \hline
\end{tabular}

Note: Entries are the productivity levels of males and females, using 2000 data from the Consumer Population Survey. These levels are constructed as hourly wages for each type -see text for details.

Table 2: Distribution of Married Working Households by Type, $\%$

\begin{tabular}{cccccc}
\hline \hline & \multicolumn{5}{c}{ Female } \\
\cline { 2 - 6 } Male & $<$ hs & hs & sc & col & $>$ col \\
\cline { 2 - 6 }$<$ hs & 6.76 & 4.24 & 2.32 & 0.39 & 0.17 \\
hs & 3.15 & 13.49 & 7.29 & 1.83 & 0.68 \\
sc & 1.75 & 7.44 & 13.51 & 4.32 & 1.56 \\
col & 0.39 & 2.36 & 5.76 & 7.58 & 2.61 \\
$>$ col & 0.17 & 0.90 & 2.63 & 4.42 & 4.27 \\
\hline \hline
\end{tabular}

Note: Entries show the fractions of the total married pool, by wife and husband educational categories. The data used are from the U.S. 2000 Census -see text for details. 
Table 3: Fraction of Agents By Type, By Gender, and Marital Status

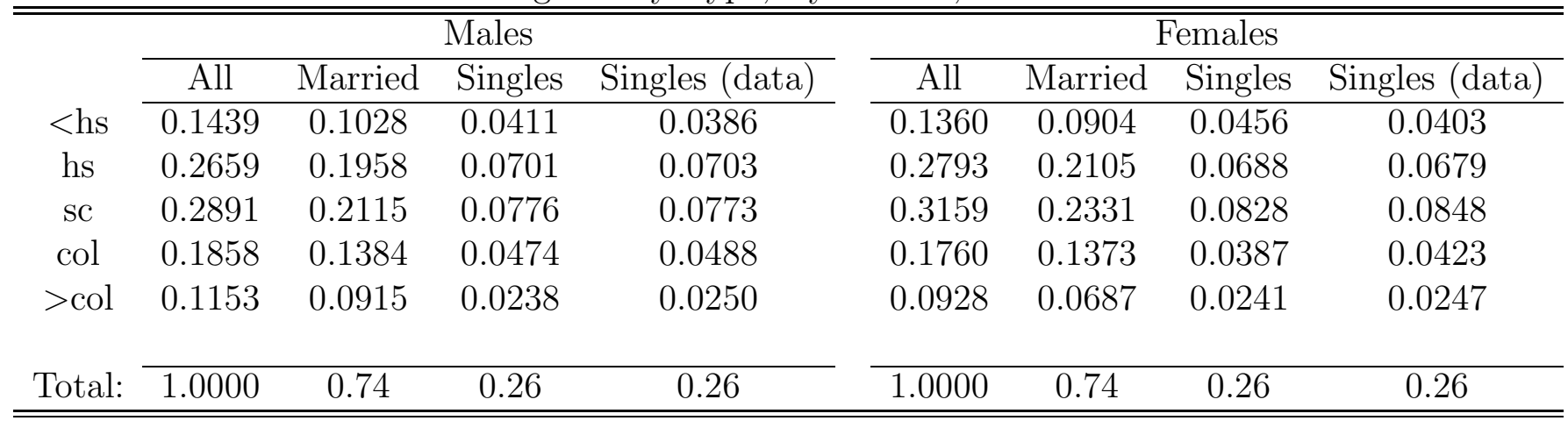

Note: Entries show the fraction of individuals in each educational category, by marital status, constructed under the assumption of a stationary population structure -see text for details. The last column in each panel shows the corresponding values in U.S. 2000 Census data.

\begin{tabular}{rcc}
\multicolumn{3}{c}{ Table 4: Tax Parameters } \\
\hline \hline & $\widehat{\eta}_{1}$ & $\widehat{\eta}_{2}$ \\
\hline Married & 0.1023 & 0.0733 \\
$R^{2}$ & & 0.99 \\
& & \\
\hline & & \\
Single & 0.1547 & 0.0497 \\
$R^{2}$ & & 0.93 \\
\hline \hline
\end{tabular}

Note: Entries show the parameter estimates for the postulated tax function. These result from regressing effective average tax rates against household income, using 2000 data from the U.S. Internal Revenue Service - see text for details. 
Table 5: Labor Force Participation of Married Females (\%)

\begin{tabular}{cccccc}
\hline \hline & \multicolumn{5}{c}{ Female } \\
\cline { 3 - 6 } Male & $<\mathrm{hs}$ & $\mathrm{hs}$ & $\mathrm{sc}$ & $\mathrm{col}$ & $>$ col \\
\cline { 1 - 4 }$<\mathrm{hs}$ & 41.1 & 62.5 & 72.1 & 77.4 & 70.9 \\
$\mathrm{hs}$ & 49.1 & 67.7 & 77.6 & 84.3 & 86.6 \\
$\mathrm{sc}$ & 50.1 & 68.1 & 74.9 & 82.9 & 88.9 \\
col & 49.5 & 64.4 & 68.8 & 73.4 & 83.7 \\
$>$ col & 45.8 & 58.4 & 62.8 & 64.1 & 79.1 \\
& & & & & \\
\cline { 2 - 6 } Total & 44.8 & 66.5 & 73.2 & 74.6 & 82.5 \\
\hline \hline
\end{tabular}

Note: Each entry shows the labor force participation of married females, calculated from 2000 data from the Consumer Population Survey -see text for details. The outer row shows the weighted average for a fixed male or female type. 
Table 6: Parameter Values

\begin{tabular}{l|c|c}
\hline \hline Parameter & $\frac{\text { Value }}{0.973}$ & Calibrated - matches $K / Y$ \\
Discount Factor $(\beta)$ & 0.4 & Literature estimates. \\
Intertemporal Elasticity (Labor Supply) $(\gamma)$ & 6 & Calibrated - matches hours per worker \\
Disutility of Market Work $(B)$ & 0.317 & Calibrated - see text. \\
Capital Share $(\alpha)$ & 0.07 & Calibrated - see text. \\
Depreciation Rate $\left(\delta_{k}\right)$ & $1 / 40$ & Calibrated - implies average \\
Probability of Retirement & & working life of 40 years \\
& 0.0982 & Calibrated - implies fraction \\
Mortality rate $(\delta)$ & 0.086 & of retired people in data. \\
& 0.124 & Calibrated - balances budget \\
Cayroll Tax Rate $\left(\tau_{p}\right)$ & & collections \\
Capital Income Tax Rate $\left(\tau_{k}\right)$ & - & Gammate Distribution - matches \\
& & LFP by education \\
Distribution of utility costs $\zeta(. \mid z)$ & conditional on husband's type \\
\hline \hline
\end{tabular}

Table 7: Model and Data

\begin{tabular}{lcc}
\hline \hline Statistic & $\underline{\text { Data }}$ & $\underline{\underline{M} \text { Model }}$ \\
Capital Output Ratio & 2.325 & 2.321 \\
Labor Hours Per-Worker & 0.408 & 0.408 \\
\hline Participation rate of Married Females(\%) & & \\
& & \\
Less than High School & 44.8 & 45.0 \\
High School & 66.5 & 66.1 \\
Less than College & 73.2 & 72.9 \\
College & 74.6 & 77.5 \\
More than College & 82.5 & 81.6 \\
& & \\
Total & 68.9 & 69.2 \\
\hline \hline
\end{tabular}

Note: Entries summarize the performance of the benchmark model in terms of the stated targets. 
Table 8: Proportional Taxes (\% change)

\begin{tabular}{lcc}
\hline \hline & $\begin{array}{c}\text { Consumption } \\
\text { Tax }\end{array}$ & $\begin{array}{c}\text { Income } \\
\text { Tax }\end{array}$ \\
\hline Labor Force Participation & 7.3 & 6.2 \\
Aggregate Hours & 4.7 & 4.3 \\
Aggregate Hours (Married Females) & 10.6 & 9.3 \\
Hours per worker (female) & 2.6 & 2.3 \\
Hours per worker (male) & 2.8 & 2.6 \\
Labor Input & 4.2 & 3.8 \\
Capital/Output & 15.0 & 4.5 \\
Aggregate Output & 11.2 & 5.9 \\
Wage & 6.5 & 2.0 \\
\hline Tax rate (\%) & 17.8 & 12.7 \\
\hline \hline
\end{tabular}

NOTE: The results for a "consumption (income) tax" pertain to the replacement of current income taxes by a proportional consumption (income) tax. The values for "Tax Rate" correspond to the proportional rates that are necessary to achieve budget balance. 
Table 9: Progressive Taxes (\% change)

\begin{tabular}{lccc}
\hline \hline & \multicolumn{2}{c}{ Progressive Consumption Tax } & Separate Filing \\
\cline { 2 - 3 } & High Exemption & Low Exemption & \\
\hline Labor Force Participation & 3.2 & 6.3 & 5.9 \\
Aggregate Hours & 1.5 & 3.6 & 2.1 \\
Aggregate Hours (Married Females) & 4.4 & 8.7 & 7.3 \\
Hours per worker (female) & 0.3 & 1.5 & 0.8 \\
Hours per worker (male) & 0.9 & 2.1 & 0.2 \\
Labor Input & 1.5 & 3.2 & 1.6 \\
Capital/Output & 14.4 & 14.2 & 2.1 \\
Aggregate Output & 8.0 & 9.8 & 2.6 \\
Wage & 6.3 & 6.3 & 0.9 \\
\hline Tax Rate (\%) & 27.5 & 21.5 & $-1.5 \%$ \\
\hline \hline
\end{tabular}

Note: Results in the first two columns pertain to the introduction of a progressive consumption tax, which consists of an exemption level and a common tax rate applied above this level. The "high" ("low") exemption level corresponds to $1 / 3$ $(1 / 6)$ mean consumption for single individuals, and 1/2 (1/4) mean consumption for married households in the benchmark economy. The last column shows the effects of taxing individuals rather than households, as explained in the text. The values for "Tax Rate" correspond to the proportional rates that are necessary to achieve budget balance. 
Table 10: Contribution of Married Females to Changes in Labor Supply (\%)

\begin{tabular}{cccccc}
\hline \hline & $\begin{array}{c}\text { Propor. } \\
\text { Cons. }\end{array}$ & $\begin{array}{c}\text { Propor. } \\
\text { Inc. }\end{array}$ & $\begin{array}{c}\text { Progr. } \\
\text { Cons. } \\
\text { (high exemp. })\end{array}$ & $\begin{array}{c}\text { Progr. } \\
\text { Cons. } \\
\text { (low exemp. })\end{array}$ & $\begin{array}{c}\text { Separate } \\
\text { Filing }\end{array}$ \\
\hline \hline Panel A: Total Changes & & & & & \\
& & & & & \\
$\begin{array}{c}\Delta \text { in Married Female Hours } \\
(\% \text { of Total } \Delta \text { in Hours })\end{array}$ & 59.3 & 58.1 & 80.1 & 64.9 & 91.4 \\
\hline $\begin{array}{c}\Delta \text { in Married Female Labor } \\
(\% \text { of Total } \Delta \text { in Labor })\end{array}$ & 50.5 & 49.4 & 65.2 & 55.0 & 88.6 \\
\hline \begin{tabular}{c} 
Panel B: Extensive Margin \\
\hline in Married Female Hours \\
$(\%$ of Total $\Delta$ in Hours $)$
\end{tabular} & 51.5 & 49.6 & 71.0 & 56.8 & 82.0 \\
\hline $\begin{array}{c}\Delta \text { in Married Female Labor } \\
(\% \text { of Total } \Delta \text { in Labor })\end{array}$ & 42.7 & 40.7 & 55.4 & 46.7 & 77.0 \\
\hline \hline
\end{tabular}

Note: The entries show the contribution of changes in the labor supply of married females relative to total changes in labor supply, both in terms of raw hours changes as well as in terms of labor in efficiency units. The top panel shows the contribution of total changes. The bottom panel shows only the contribution of changes along the extensive margin.

Table 11: Changes in Labor Force Participation

\begin{tabular}{cccccc}
\hline \hline Female Type & $\begin{array}{c}\text { Propor. } \\
\text { Cons. }\end{array}$ & $\begin{array}{c}\text { Propor. } \\
\text { Inc. }\end{array}$ & $\begin{array}{c}\text { Prog. } \\
\text { Cons. } \\
\text { (high exemp.) }\end{array}$ & $\begin{array}{c}\text { Prog. } \\
\text { Cons. } \\
\text { (low exemp.) }\end{array}$ & $\begin{array}{c}\text { Separate } \\
\text { Filing }\end{array}$ \\
\hline \hline$<\mathrm{hs}$ & 22.5 & 20.0 & 0.9 & 18.7 & 19.8 \\
$\mathrm{hs}$ & 9.1 & 6.3 & 6.1 & 7.6 & 6.9 \\
$\mathrm{sc}$ & 5.4 & 6.1 & 2.6 & 5.3 & 4.7 \\
$\mathrm{col}$ & 4.5 & 3.5 & 2.4 & 3.7 & 3.3 \\
$>\mathrm{col}$ & 2.7 & 1.7 & 1.0 & 2.2 & 1.7 \\
\hline \hline
\end{tabular}

Note: The entries show the percentage changes in labor force participation, arranged by the female type, for all reforms considered. 
Table 12: Reforms with Low Intertemporal Elasticity (\% change)

\begin{tabular}{lccccc}
\hline \hline & $\begin{array}{c}\text { Prop. } \\
\text { Cons. }\end{array}$ & $\begin{array}{c}\text { Prop. } \\
\text { Inc. }\end{array}$ & $\begin{array}{c}\text { Prog. } \\
\text { Cons. } \\
\text { (high exemp.) }\end{array}$ & $\begin{array}{c}\text { Prog. } \\
\text { Cons. } \\
\text { (low exemp.) }\end{array}$ & $\begin{array}{c}\text { Seperate } \\
\text { Filing }\end{array}$ \\
\hline Labor Force Participation & 11.0 & 8.9 & 5.0 & 8.4 & 5.5 \\
Aggregate Hours & 4.6 & 3.9 & 1.7 & 3.4 & 1.8 \\
Aggregate Hours (Married Fem.) & 13.0 & 10.7 & 5.8 & 9.9 & 6.2 \\
Hours per worker (female) & 1.7 & 1.5 & 0.2 & 1.2 & 0.7 \\
Hours per worker (male) & 1.4 & 1.2 & 0.2 & 0.9 & 0.0 \\
Labor Input & 3.8 & 3.2 & 1.4 & 2.8 & 1.3 \\
Aggregate output & 10.3 & 5.4 & 8.0 & 9.4 & 2.7 \\
\hline $\begin{array}{l}\text { (in Married Female Hours } \\
\text { (\% of Total } \Delta \text { in Hours) }\end{array}$ & 79.0 & 76.3 & 96.3 & 81.7 & 98.0 \\
$\begin{array}{l}\Delta \text { in Married Female Labor } \\
\text { (\% of Total } \Delta \text { in Labor) }\end{array}$ & 71.2 & 68.4 & 86.2 & 73.6 & 96.0 \\
& & & & & \\
\hline \hline
\end{tabular}

Note: Results show the aggregate consequences of tax reforms under a low value of the intertemporal elasticity parameter $(\gamma=0.2)$.

Table 13: Comparison with Standard Framework

\begin{tabular}{|c|c|c|c|c|}
\hline & \multicolumn{2}{|c|}{ High Elasticity $(\gamma=0.4)$} & \multicolumn{2}{|c|}{ "Low Elasticity $(\gamma=0.2)$} \\
\hline & $\begin{array}{c}\text { Current } \\
\text { Framework }\end{array}$ & $\begin{array}{c}\text { Standard } \\
\text { Framework }\end{array}$ & $\begin{array}{c}\text { Current } \\
\text { Framework }\end{array}$ & $\begin{array}{c}\text { Standard } \\
\text { Framework }\end{array}$ \\
\hline Aggregate Hours & 4.7 & 3.4 & 4.6 & 1.9 \\
\hline Labor Input & 4.2 & 3.5 & 3.8 & 1.9 \\
\hline Aggregate Output & 11.2 & 10.0 & 10.3 & 8.8 \\
\hline Hours per worker (male) & 2.8 & 3.5 & 1.4 & 2.0 \\
\hline
\end{tabular}

Note: The results show aggregate effects of a proportional consumption tax reform under the framework developed in this paper, and under a version of a standard macroeconomic model with a single earner as described in the text. 
Figure 1: Taxes and Labor Force Participation of Secondary Earners

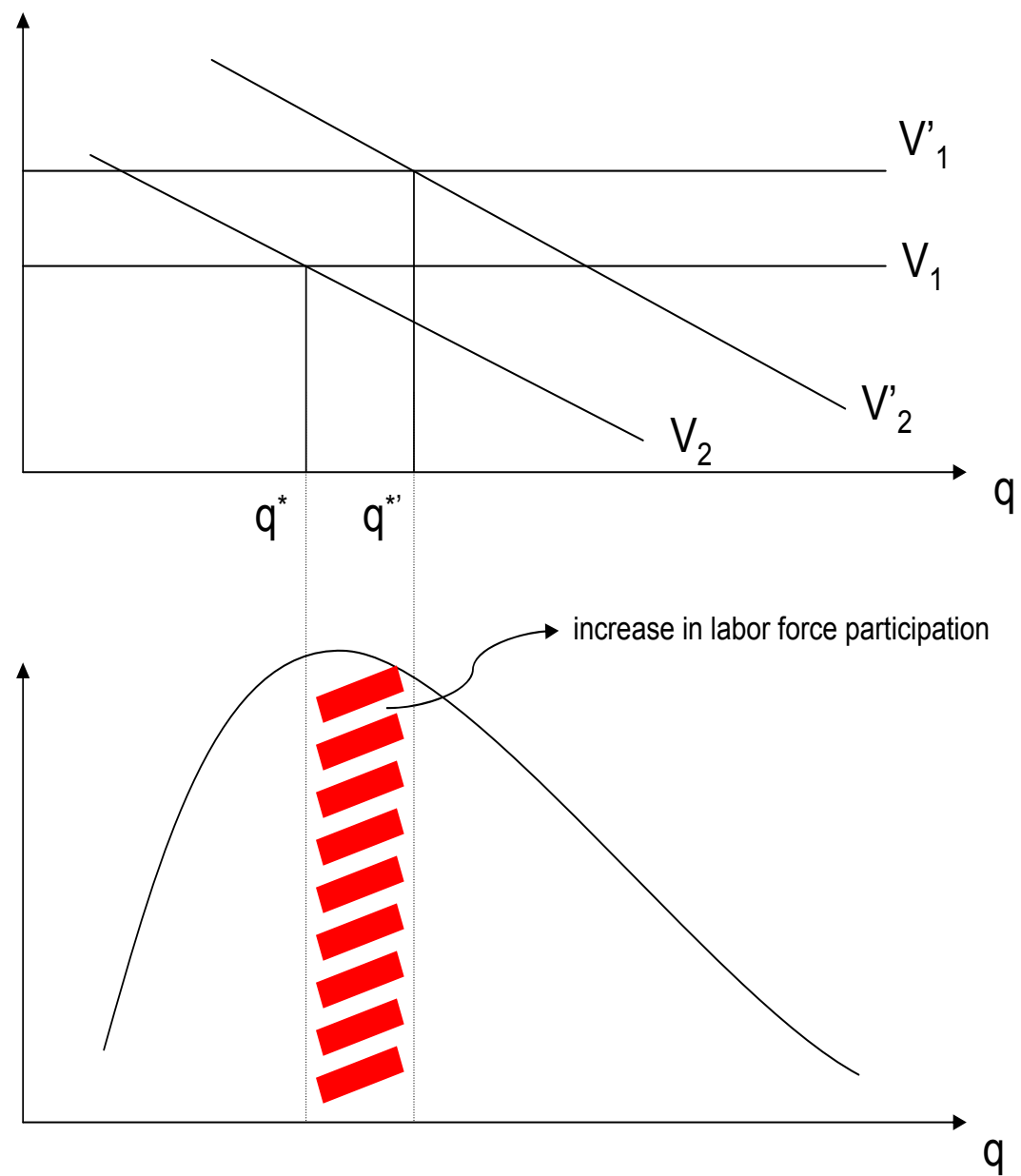



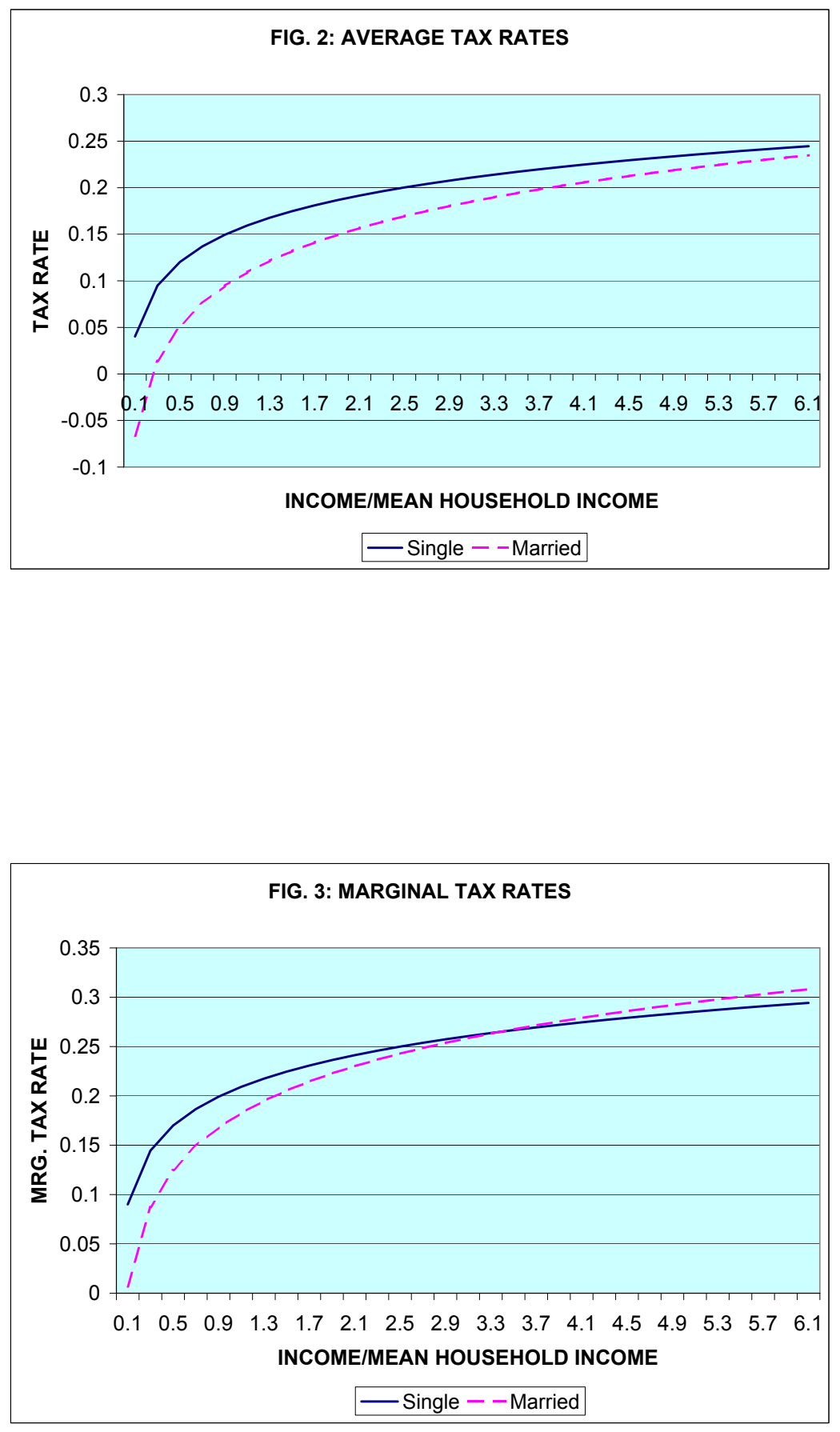


\section{References}

[1] Albanesi, Stefania and C. Olivetti, "Gender Roles and Technological Progress," NBER Working Paper 13179, June 2007.

[2] Altig, David, A. J. Auerbach, L. J. Kotlikoff, K. A. Smetters and J. Walliser, "Simulating Fundamental Tax Reform in the United States," American Economic Review, vol. 91, 3 (June 2001), 574-595.

[3] Attanasio, O., Low, H. and V. Sánchez Marcos, "Explaining Changes in Female Labor Supply in a Life-Cycle Model," American Economic Review, forthcoming.

[4] Auerbach, Alan J. and Kevin A. Hassett, Toward Fundamental Tax Reform, Washington, D.C.: The American Enterprise Institute Press, 2005.

[5] Blundell, R. and T. E. MaCurdy, "Labor Supply: A Review of Alternative Approaches," In Handbook of Labor Economics, vol. 3A, pages 1599-1695, ed. O. A. Ashenfelter and D. Card, Amsterdam: North Holland, 1999.

[6] Bosworth, B., and G. Burtless, "Effects of Tax Reform on Labor Supply, Investment, and Savings," Journal of Economic Perspectives, vol. 6, no. 1 (Winter 1992), 3-25.

[7] Castañeda, Ana, J. Díaz-Giménez and J. V, Ríos-Rull, "Accountig for the US Earnings and Wealth Inequality," Journal of Political Economy, vol. 111, 4 (August 2003), 818857.

[8] Chade, Héctor and G. Ventura, "Taxes and Marriage: A Two-Sided Search Analysis," International Economic Review, vol. 43, no. 3 (August 2002), 955-986.

[9] Chang, Yongsung and S. B. Kim. "From Individual to Aggregate Labor Supply: A Quantitative Analysis Based on a Heterogeneous-Agent Macroeconomy," International Economic Review, vol. 47, no. 1 (February 2006), 1-27.

[10] Cho, Jank-Ok., and R. Rogerson, "Family Labor Supply and Aggregate Fluctuations," Journal of Monetary Economics, vol. 21, no. 2 (March 1988), 233-245.

[11] Conesa, Juan Carlos and D. Krueger, "On the Optimal Progressivity of the Income Tax Code," Journal of Monetary Economics, vol. 53, no. 7 (October 2006), 1425-1450. 
[12] Davis, Steven J., and M. Henrekson, "Tax Effects on Work Activity, Industry Mix and Shadow Economy Size: Evidence From Rich Country Comparisons," Manuscript, University of Chicago Graduate School of Business, 2003.

[13] Diaz-Gimenez, Javier and Joseph Pijoan-Mas, "Flat Tax Reforms in the U.S.: A Boon for the Income Poor," Mimeo, University of Carlos III, Madrid, Spain, 2005.

[14] Domeij, David and M. Floden, "The Labor-Supply Elasticity and Borrowing Constraints: Why Estimates are Biased," Review of Economic Dynamics, vol. 9, no. 2 (April 2006), 242-262.

[15] Eissa, Nada, "Taxation and The Labor Supply of The Women: The Tax Reform Act of 1986 As A Natural Experiment," NBER Working Paper 5023, 1995.

[16] Eissa, Nada and H. W. Hoynes, "Behavioral Responses to Taxes: Lessons from the EITC and Labor Supply," Tax Policy and the Economy, vol. 20 (September 2006), pp. $74-110$

[17] Erosa, Andres and Koreshkova, T., "Progressive Taxation in a Dynastic Model of Human Capital," Journal of Monetary Economics, vol. 54, no. 3 (April 2007), pp. 667-685.

[18] Fernández, R., Guner, N. and John Knowles, "Love and Money: A Theoretical and Empirical Analysis of Household Sorting and Inequality," Quarterly Journal of Economics, vol. 120, no. 1 (February 2005), 273-344.

[19] Gertler, Mark, "Government Debt and Social Security in a Life-Cycle Economy," Carnegie-Rochester Conference on Public Policy, vol. 50 (1999), 61-110.

[20] Gouveia, M., and R. P. Strauss, "Effective Federal Individual Income Tax Functions: An Exploratory Empirical Analysis," National Tax Journal, vol. 40, no. 2 (June 1994), 317-339.

[21] Greenwood, Jeremy, and N. Guner, "Marriage and Divorce since World War II: Analyzing the Role of Technological Progress on the Formation of Households," NBER Working Paper 10772, 2004. 
[22] Greenwood, Jeremy, A. Sehshadri, and M. Yorukoglu, "Engines of Liberation," Review of Economic Studies, vol. 72, no. 1 (January 2005), 109-131.

[23] Guner, Nezih, G. Ventura, and Y. Xu, "Macroeconomic Implications of Size-Dependent Policies," Review of Economic Dynamics, forthcoming.

[24] Hall, Robert E. and A. Rabushka, The Flat Tax, Stanford, CA: Hoover Institute Press, 1995.

[25] Heathcote, Jonathan, K. Storesletten, and G. L. Violante. "Consumption and Labor Supply with Partial Insurance: An Analytical Framework," mimeo, 2007.

[26] Hong, Jay and J. V. Ríos-Rull, "Social Security, Life Insurance and Annuities for Families", Journal of Monetary Economics, vol. 54, no. 1 (2007), 118-140.

[27] Internal Revenue Service Statistic of Income Division, Individual Income Tax Returns, 1980, 1985, 1990, 1995 and 2000.

[28] Jones, Larry, R. Manuelli and E. MacGrattan, "Why Are Married Women Working so Much?" Staff Report 317, Federal Reserve Bank of Minneapolis, 2003.

[29] Kaygusuz, Remzi, "Taxes and Female Labor Supply," Manuscript, The Pennsylvania State University, 2006a.

[30] Kaygusuz, Remzi, "Social Security and Two-Earner Households," Manuscript, The Pennsylvania State University, 2006b.

[31] Kleven, Henrik J. and C. T. Kreiner, "The Efficient Taxation of Couples," Manuscript, University of Copenhagen, 2006.

[32] Knowles, John. "Why Are Married Men Working So Much?" Manuscript, The University of Pennsylvania, 2007.

[33] Mulligan, Casey B., "Aggregate Implications of Indivisible Labor," Advances in Macroeconomics, vol.1, no.1, 2001.

[34] Nishiyama, Shinichi and K. Smetters, "Consumption Taxes and Economic Efficiency with Idiosyncratic Wage Shocks," Journal of Political Economy, vol. 113, no. 5 (October 2005), 1088-1115. 
[35] Olovsson, Conny, "Why Do Europeans Work So Little?" International Economic Review, forthcoming.

[36] Prescott, Edward C., "Why Do Americans Work So Much More Than Europeans?" Federal Reserve Bank of Minneapolis Quarterly Review (July 2004), 2-13.

[37] Rogerson, Richard "Understanding Differences in Hours Worked," Review of Economic Dynamics, vol. 9, no. 3 (July 2006), 365-409.

[38] Rupert, Peter, R. Rogerson, and R. Wright, "Homework in Labor Economics," Journal of Monetary Economics, vol. 46, no. 3 (December 2000), 557-579.

[39] Triest, Robert K. "The Effects of Income Taxation on Labor Supply in the United States," Journal of Human Resources, vol. 25, no. 3 (Summer 1990), 491-516.

[40] Ventura, Gustavo, "Flat Tax Reform: A Quantitative Exploration," Journal of Economic Dynamics and Control, vol. 23, no. 9-10 (September 1999), 1425-1458. 